\title{
Decifrando a proveniência dos folhelhos da formação Ponta Grossa na região de Rio Verde de Mato Grosso e Coxim (MS) através de métodos petrográficos e geoquímicos
}

Deciphering the provenance of the Ponta Grossa formation shales in the region of

Rio Verde de Mato Grosso and Coxim (State of Mato Grosso, Brazil) using petrographic and geochemical methods

\author{
Cibele Carolina Montibeller ${ }^{1}$, Antenor Zanardo e Guillermo Rafael Beltran Navarro ${ }^{2}$ \\ ${ }^{1}$ Universidade Estadual Paulista - UNESP, Instituto de Geociências e Ciências Exatas, Pós-graduação em Geociências e Meio \\ Ambiente, Avenida 24-A, 1515, Bela Vista, CEP 13506-900, Rio Claro, SP, Brasil (cibele.cm@outlook.com) \\ Universidade Estadual Paulista - UNESP, Instituto de Geociências e Ciências Exatas, Departamento de Petrologia e \\ Metalogenia, Rio Claro, SP, Brasil (azanardo@rc.unesp.br; navarro@rc.unesp.br)
}

Recebido em 9 de junho de 2015; aceito em 10 de agosto de 2016

\begin{abstract}
Resumo
Na região de Rio Verde de Mato Grosso e Coxim (MS) ocorrem rochas sedimentares devonianas relacionadas à Formação Ponta Grossa. Nesta região, a Formação Ponta Grossa aflorante é constituída por um pacote de folhelhos e siltitos cinza a pretos, com níveis de siltitos argilosos sobrepostos por arenitos feldspáticos muito finos micáceos, de cores creme, verde e avermelhados. Acima dos arenitos ocorrem siltitos argilosos amarelos fracamente laminados. Quimicamente, os níveis pelíticos são classificados como folhelhos/argilitos e com composição matura, derivados principalmente de rochas ígneas intermediárias e/ou máficas. Através da utilização de diagramas discriminantes para ambientes tectônicos e de proveniência, não foi estabelecido um padrão único para as amostras da Formação Ponta Grossa, podendo ser tanto classificados como sedimentos depositados em margem passiva quanto em margem ativa. Entretanto, dado o contexto da Bacia do Paraná durante o Devoniano, os sedimentos da Formação Ponta Grossa provavelmente tiveram como fonte rochas formadas em margens ativas (arcos magmáticos), erodidas e depositadas em margem passiva (bacia intracratônica).
\end{abstract}

Palavras-chave: Litogeoquímica; Devoniano; Bacia do Paraná.

\begin{abstract}
In the region of Rio Verde de Mato Grosso and Coxim (State of Mato Grosso do Sul, Brazil) Devonian sedimentary rocks related to the Ponta Grossa Formation occur. In this region, the Ponta Grossa Formation outcrops consist on a sequence of gray to black shales and siltstones, with levels of cream, green and reddish clayey siltstones overlain by very fine feldspathic and micaceous sandstones. Weakly structured, yellow clayey siltstones occur above the sandstones. Chemically, these pelitic levels are classified as mature shales/mudstones, derived mainly from intermediate and/or mafic igneous rocks. Diagrams used for provenance and tectonic setting discrimination revealed that these Ponta Grossa Formation sediments may have more than one origin, as they can be classified as deposited in passive or active margins. However, given the tectonic setting of the Paraná Basin during the Devonian, the source of these sediments is likely to be rocks formed in active margins (magmatic arcs), which were eroded and the resulting sediments deposited in passive margins (intracratonic basin).
\end{abstract}

Keywords: Lithogeochemistry; Devonian; Paraná Basin. 


\section{INTRODUÇÃO}

A Bacia do Paraná é uma bacia sedimentar intracratônica com geometria de sinéclise, localizada no centro-sul do continente sul-americano. A bacia ocupa cerca de $1.100 .000 \mathrm{~km}^{2}$ do Brasil meridional, e mais $300.000 \mathrm{~km}^{2}$ distribuídos entre o Paraguai oriental, o nordeste da Argentina e o norte do Uruguai (Milani et al., 2007; Pereira et al., 2012). Apesar de a Bacia do Paraná ser uma bacia com ampla distribuição geográfica, os estudos geoquímicos das rochas que a compõem são ainda muito escassos, sendo poucos os trabalhos que se dedicaram à geração de padrões geoquímicos das unidades sedimentares que a formam. A geração destes padrões poderia dar indícios das rochas que contribuíram para a formação dos sedimentos da Bacia do Paraná, principalmente no caso de sequências pelíticas que, segundo Rollinson (1993), pertencem à fração granulométrica dos sedimentos que melhor preserva a assinatura geoquímica da fonte.

A abordagem geoquímica de sequências sedimentares detríticas, com vistas à determinação das características das áreas fonte dos sedimentos, é um tema recorrente no cenário internacional, mas guarda certo ineditismo no Brasil. Diversos autores (por exemplo Bhatia, 1983; Bhatia e Crook, 1986; McLennan et al., 1993; Garver e Scott, 1995; Mongelli, 1995; Garver et al., 1996; Mongelli et al., 1996; Pearce et al., 1999; Hassan et al., 1999; Taylor e Macquaker, 2000; Amorosi et al., 2002; Cullers, 1994, 1995, 2000, 2002; Armstrong-Altrin e Verma, 2005; Selvaraj e Chen, 2006; Armstrong-Altrin, 2009; Bakkiaraj et al., 2010; Raza et al., 2012; Fatima e Khan, 2012) vêm utilizando a classificação geoquímica de rochas sedimentares com sucesso para determinar as condições de intemperismo nas áreas fontes, proveniência e as condições tectônicas destas áreas que alimentam bacias sedimentares, e os resultados são de grande valor para o estudo da dinâmica destas bacias. Este trabalho, portanto, tem como objetivo apresentar dados geoquímicos das rochas pelíticas que afloram na região dos municípios de Rio Verde de Mato Grosso e Coxim (MS) e que são relacionadas à Formação Ponta Grossa, visando contribuir para as discussões acerca da origem destas sucessões sedimentares e de sua contextualização na Plataforma Sul-Americana.

\section{CONTEXTO GEOLÓGICO}

A área de estudo está inserida no contexto da borda noroeste da Bacia do Paraná, no Estado do Mato Grosso do Sul, sendo que a cerca de $20 \mathrm{~km}$ a oeste afloram rochas neoproterozoicas da Faixa Paraguai e sedimentos cenozoicos da Bacia do Pantanal. Milani (1997) considera seis supersequências nos registros sedimentares da Bacia do Paraná: Rio Ivaí (Ordoviciano-Siluriano), Paraná (Devoniano), Gondwana I (Carbonífero-Eotriássico), Gondwana II (Meso a Neotriássico), Gondwana III (Neojurássico-Eocretáceo)

e Bauru (Neocretáceo).

A Supersequência Paraná corresponde aos sedimentos devonianos inicialmente definidos por Evans (1894) como a "Série Chapada" aflorante no Estado de Mato Grosso. Em termos estratigráficos, a Supersequência Paraná corresponde ao Grupo Paraná, que apresenta espessura máxima de $800 \mathrm{~m}$, e em geral ocorre assentada sobre os sedimentos da Supersequência Rio Ivaí, embora seja também registrada como depositada diretamente sobre o embasamento da Bacia do Paraná.

No Estado do Mato Grosso do Sul, o Grupo Paraná aflora em uma faixa aproximadamente contínua e pouco espessa com direção NNE-SSW (Figura 1), que se estende desde cerca de $10 \mathrm{~km}$ a norte do município de Aquidauana até o município de Sonora (extremo norte do Estado) (Lacerda Filho et al., 2006). Este grupo, na região, ocorre sobre sedimentos do Grupo Rio Ivaí (Supersequência Rio Ivaí de idade Ordoviciana-Siluriana), e sob sedimentos da Formação Aquidauana (Supersequência Gondwana I, de idade Carbonífera-Eotriássica) (Lacerda Filho et al., 2006).

Lange e Petri (1967) propõem a divisão do intervalo devoniano da Bacia em Formação Furnas e Formação Ponta Grossa, sendo esta última subdividida em membros Jaguariaíva, Tibagi e São Domingos. Grahn (1992), Gaugris e Grahn (2006) e Grahn et al. (2000, 2002, 2010), considerando que a Bacia do Paraná é representada no Brasil por dois depocentros, culminando em duas sub-bacias (Alto Garças a norte e Apucarana a sul), modificaram as subdivisões da sub-bacia de Apucarana, elevando o Membro São Domingos para a categoria de Formação. Bosetti et al. (2012) citam a correlação entre as sub-bacias de Alto Garças e Apucarana segundo seu conteúdo fossilífero, afirmando que a Formação Ponta Grossa, no sentido atribuído por Grahn et al. (2000, 2002, 2010, 2013), representa um trend transgressivo, em direção à Superfície de Inundação Máxima do intervalo considerado, a partir da qual é registrado um hiato deposicional correspondente ao Emsiano Médio, posteriormente dando lugar a pelo menos três ciclos transgressivo-regressivos, assim compondo um ciclo de afogamento completo representado pela citada Formação São Domingos.

Segundo Assine et al. (1994), a sequência devoniana da Bacia do Paraná inicia-se com um pacote psamítico/psefítico continental, sendo gradualmente sobreposto por sedimentos litorâneos e marinhos de água rasa, num intervalo definido como a base de um grande ciclo transgressivo-regressivo. Ocorre então uma rápida transgressão representada pelos folhelhos marinhos da Formação Ponta Grossa (no sentido de Lange e Petri, 1967), que cobrem os arenitos da Formação Furnas, em contato gradual e sem interdigitações significativas, caracterizado pelo intervalo denominado "camadas de transição" (Petri, 1948 apud Assine et al., 1994). Também segundo Assine et al. (1994), podem ser distinguidas duas superfícies de inundação máxima nos folhelhos da Formação 


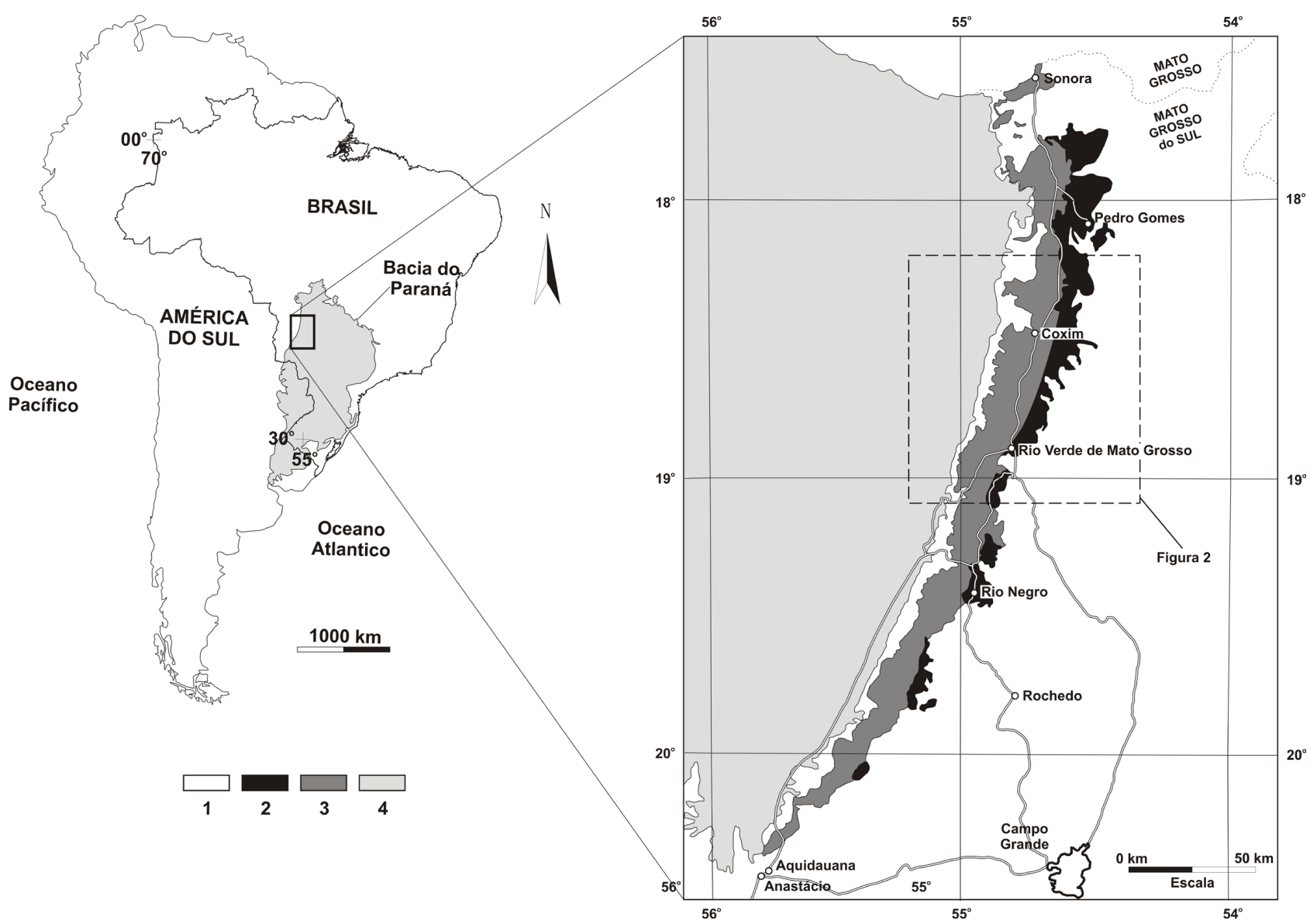

Figura 1. Área de afloramento das unidades devonianas da Bacia do Paraná no Estado do Mato Grosso do Sul; 1 - Outras unidades da Bacia do Paraná e afloramento de unidades neoproterozoicas da Faixa Paraguai-Araguaia; 2 - Formação Ponta Grossa (Devoniano); 3 - Formação Furnas (Devoniano); 4 - Áreas correspondentes à Bacia do Pantanal (Cenozoico) (modificado de Lacerda Filho et al., 2006).

Ponta Grossa, que seriam parte do evento transgressivo global do Devoniano Médio. Outros autores (por exemplo Zabini et al., 2012; Grahn et al., 2013; Horodyski et al., 2014) apresentam discussões no campo da estratigrafia de sequências da Formação Ponta Grossa na sub-bacia de Apucarana, na região do município de Tibagi (PR). As características litológicas das unidades que compõem a sequência devoniana da Bacia do Paraná são:

Formação Furnas: Segundo Milani et al. (2007), a Formação Furnas corresponde a "uma sucessão de arenitos quartzosos brancos, médios a grossos, caulínicos e exibindo estratificações cruzadas de várias naturezas", sendo que próximo à base são frequentemente descritos leitos conglomeráticos, na porção intermediária dominam arenitos de granulometria média intercalados a siltitos e folhelhos muscovíticos, e no topo ocorrem arenitos médios a grossos intercalados a camadas de arenitos muito finos com estratificação do tipo hummocky. Ainda segundo Milani et al. (2007), a natureza do contato entre a Formação Furnas e a Formação Ponta
Grossa (determinada através de perfis de raios gama) é marcada pelo incremento contínuo na argilosidade da Formação Furnas, indicando passagem gradacional para a Formação Ponta Grossa.

Formação Ponta Grossa: A Formação Ponta Grossa apresenta na base uma sequência de afogamento dos sistemas deposicionais transicionais da Formação Furnas, representada por um espesso pacote de folhelhos intercalados a delgadas lentes de arenito fino com marcas de ondas, correspondente no Estado do Paraná ao Membro Jaguariaíva. Esta sequência é sobreposta por um pacote de folhelhos pretos carbonosos, sucedidos por um pacote silto-arenoso correspondente ao Membro Tibagi. A última sequência descrita na literatura corresponde ao Membro São Domingos, de natureza predominantemente pelítica, que é interpretada como o registro do afogamento dos sistemas anteriores, encerrando o registro devoniano na Bacia do Paraná (Milani et al., 2007).

O Membro Jaguariaíva está descrito por Lange e Petri (1967) como sobreposto à Formação Furnas com contato 
concordante e gradacional, com a parte basal consistindo em uma sequência de sete metros de espessura de siltitos intercalados com arenitos grossos, sendo ambos fossilíferos. Na seção-tipo (município de Ponta Grossa - PR), é constituído por folhelhos argilosos, siltosos ou arenosos com arenitos finos a muito finos subordinados. Logo acima, são encontrados folhelhos argilosos pretos, carbonáceos, com nódulos calcários na base. Concreções sideríticas e calcárias são comuns do meio para o topo da sequência, com formas regulares a irregulares, com comprimentos de até $1 \mathrm{~m}$, mas espessuras de no máximo alguns centímetros. Em locais diferentes da seção-tipo, este membro é constituído por folhelhos cinza com cores claras variegadas para o topo, em decorrência do intemperismo. A estrutura pode variar de finamente laminada até estratos centimétricos maciços, e os estratos laminados costumam ser altamente micáceos. A presença de pirita é comum, principalmente nos folhelhos pretos (Lange e Petri, 1967).

O Membro Tibagi na seção-tipo (município de Ponta Grossa - PR) é descrito como um pacote de $20 \mathrm{~m}$ de espessura de arenitos siltosos, micáceos e finos, com alguma variação na granulometria. Os contatos inferior e superior com os outros membros da Formação Ponta Grossa são descritos como transicionais. Em outras localidades, são descritos como arenitos cinza-claro com cores de alteração amarelo-ocre ou vermelho amarelado. Na base, são mais argilosos, micáceos e laminados, passando para o topo para arenitos com estratificação incipiente, finos a médios e micáceos, e então novamente transicionando para o topo para arenitos laminados argilosos, terminando em folhelhos micáceos duros. Esta sucessão de fácies pode se repetir várias vezes na coluna estratigráfica e também pode estar intercalada com folhelhos ou ser mais homogênea e contínua (Lange e Petri, 1967).

Lange e Petri (1967) apresentam o Membro São Domingos como um pacote aflorante de $90 \mathrm{~m}$ na seção-tipo (margem esquerda do Rio Tibagi - PR), composto por folhelhos predominantemente mais argilosos que o Membro Jaguariaíva, com camadas betuminosas, e frequentemente intercalados com camadas grossas com laminações vermelhas e pretas. Em outras localidades, o Membro São Domingos é composto por folhelhos com cores mais escuras que o Membro Jaguariaíva, em geral cinza a cinza-escuro e até mesmo pretos quando betuminosos. A alteração superficial confere a este pacote cores verde-claras ou cinza avermelhadas. Na base, esta sequência apresenta grãos de fração areia dispersos de forma irregular, e próximo ao município de Ponta Grossa (PR), possui uma camada de $15 \mathrm{~cm}$ de espessura de arenito fino argiloso mal selecionado com grande quantidade de seixos de quartzo e quartzito menores que $1 \mathrm{~cm}$ de diâmetro, com forma discoide. Esta camada é superposta por uma fina camada de folhelho micáceo rica em restos vegetais. Lange e Petri (1967) consideram que as rochas da Formação Ponta Grossa aflorantes na Chapada dos Guimarães, em Mato
Grosso, são correspondentes ao Membro São Domingos, que, na região, é composto por camadas periodicamente repetidas de intercalações entre folhelhos pretos, siltitos finamente laminados, às vezes com estratificação cruzada, e arenitos finos de cor clara, laminados e micáceos.

\section{MATERIAIS E MÉTODOS}

Foram realizadas descrições petrográficas e análises geoquímicas de rocha total em 19 amostras de rochas sedimentares pelíticas da Formação Ponta Grossa, provenientes da região dos municípios de Rio Verde de Mato Grosso e Coxim (MS). As amostras foram coletadas em frentes de lavra de argila para as indústrias do Arranjo Produtivo Local (APL) Terra Cozida do Pantanal, que corresponde a um aglomerado industrial com finalidade de produção de peças cerâmicas. As descrições petrográficas foram realizadas à luz transmitida, seguindo a classificação petrográfica sugerida por Heinrich (1972). As mesmas amostras foram enviadas para análises químicas (rocha total), executadas pelo Laboratório Acme (Analytical Laboratories LTD, Vancouver, Canadá), sendo os elementos maiores analisados por Espectrometria de Emissão Atômica por Plasma Acoplado Indutivamente (ICP-OES), após fusão utilizando metaborato/tetraborato de lítio e digestão em ácido nítrico diluído, e a perda ao fogo (LOI) determinada pela diferença de peso da amostra antes e depois do aquecimento a $1000^{\circ} \mathrm{C}$ por quatro horas. Os elementos traços e os elementos terras raras (ETR) foram analisados por Espectrômetro de Massa em Plasma Indutivamente Acoplado (ICP-MS), após fusão utilizando metaborato/tetraborato de lítio e digestão em ácido nítrico, sendo que para os metais $\mathrm{Cu}, \mathrm{Ni}, \mathrm{Pb}$ e Zn, a digestão foi por água régia. $\mathrm{O}$ tratamento dos dados geoquímicos e a construção de diagramas foram realizados com emprego do programa PETROGRAPH versão 2 beta dic2007 (Petrelli et al., 2005).

\section{GEOLOGIA LOCAL}

Foram visitadas cinco frentes de lavras em Rio Verde de Mato Grosso, denominadas de minas M1, M2, M3 e M5, e uma lavra em operação em Coxim, denominada mina M6 (Figura 2). A coleta de material para análise foi feita nas frentes de lavra, por estas apresentarem melhor exposição de material fresco e in situ. Todas as minas possuem similaridades litológicas marcantes, sendo consideradas pertencentes ao mesmo pacote estratigráfico (Formação Ponta Grossa).

Da base para o topo, as minas apresentam a mesma sucessão de fácies, que podem alcançar até 18 metros de espessura (Figura 3, mina M1): i) pacote relativamente homogêneo de folhelhos cinza-escuros a pretos, carbonáticos ou não, progressivamente intemperizados para o topo, com espessura média de 10 metros; ii) pacote de cerca de 


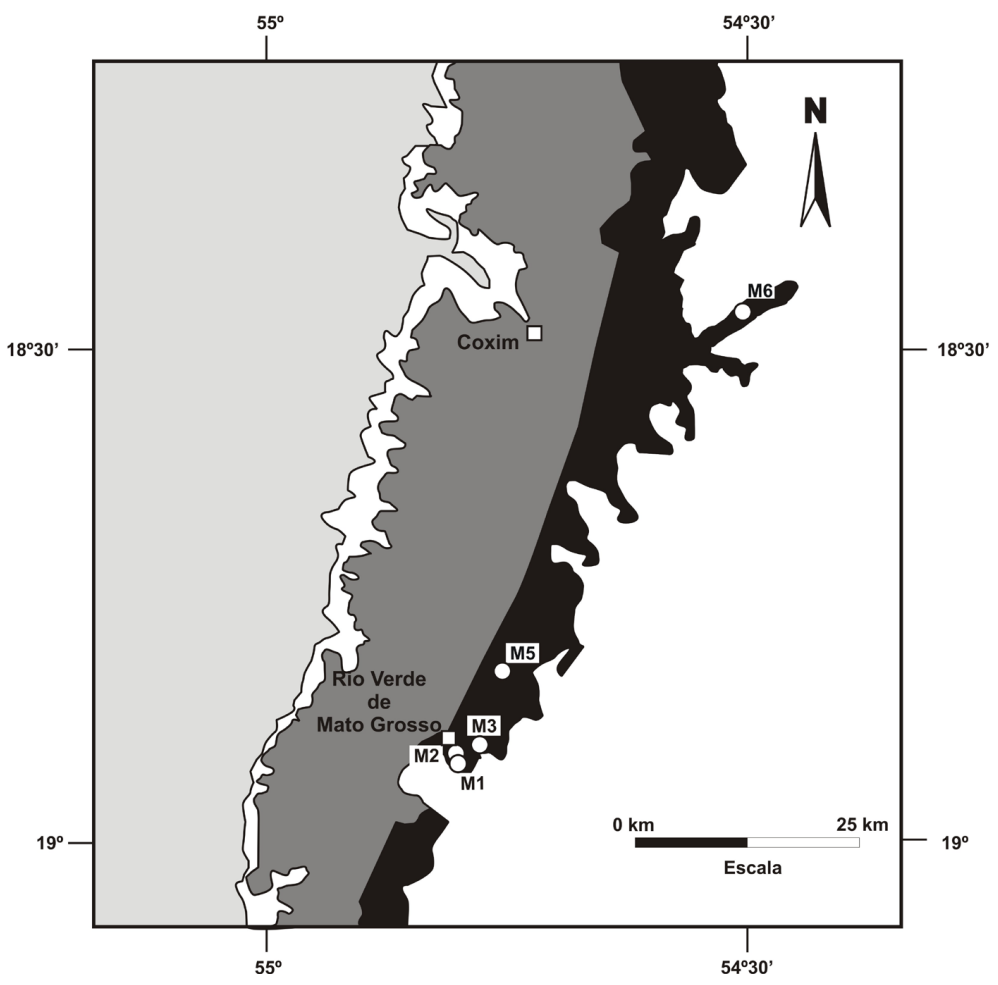

- Sedes municipais

O Minas visitadas

\begin{tabular}{|c|}
\hline $\begin{array}{l}\text { Áreas correspondentes à Bacia do } \\
\text { Pantanal(Cenozoico) }\end{array}$ \\
\hline $\begin{array}{l}\text { Outras unidades da Bacia do Paraná e } \\
\text { a f I o r a m e n t o de u n i d a de s } \\
\text { neoproterozoicas da Faixa Paraguai- } \\
\text { Araguaia }\end{array}$ \\
\hline Formação Ponta Grossa (Devoniano) \\
\hline Formação Furnas (Devoniano) \\
\hline
\end{tabular}

Figura 2. Mapa geológico com a localização das minas visitadas. Mapa geológico modificado de Lacerda Filho et al. (2006).

3 metros de espessura, composto por arenitos feldspáticos muito finos micáceos que se sucedem aos folhelhos através de intercalações progressivamente mais abundantes e mais espessas, e iii) pacote de siltitos argilosos e argilitos, que em todos os casos observados estão bem alterados, apresentando cor amarelada a avermelhada, relativamente homogêneos com laminação incipientemente preservada, com espessura variável de acordo com a exposição (espessura máxima observada em Rio Verde é de aproximadamente $5 \mathrm{~m}$ ). A mina M6 localizada a leste da sede do município de Coxim possui espessura da ordem de $6 \mathrm{~m}$ e não foram observados os níveis de arenito feldspático fino presentes nas outras minas. Os tipos de filossilicatos da base da mina M6, determinados através de difratometria de raios X, são semelhantes aos identificados no topo da sequência em outras minas, não sendo encontrados nos níveis inferiores destas, o que sugere que a mina M6 provavelmente corresponde à porção superior da estratigrafia observada.

Os folhelhos da base da sequência litoestratigráfica podem ser divididos em três subníveis, que são bem exemplificados pela exposição na mina M1 (Figura 3). A correlação entre as seções estudadas (minas M1, M2, M3, M5 e M6) e a posição dos níveis definidos para coleta de amostras e análise (de A a F) podem ser observadas na Figura 4.

Na base, os folhelhos são de cor cinza-escuro a preto, laminados e com carbonatos (siderita) e ferruginosos (nível A). Para o topo, os folhelhos têm cor cinza levemente amarelada, com menor presença de carbonatos (lixiviação?), e obliteração parcial da laminação proeminente observada nos folhelhos (nível B). Neste nível, ocorre uma faixa fosfática de espessura centimétrica a decimétrica, descontínua, constituída por nódulos e lentes de cor cinza-claro, localmente com leve matiz avermelhado, contendo delgadas crostas de calcita em fraturas e granulação muito fina quase afanítica gerando aspecto siltoso. O topo do pacote de folhelhos tem como característica a cor amarela acinzentada com resquícios de rocha de cor cinza, pouco ou nenhum registro de carbonatos, e aumento significativo da proporção de argilominerais. A estrutura laminada dos folhelhos é ainda menos proeminente neste material, conferindo em certos locais um aspecto maciço a este pacote (nível C).

O contato do pacote de folhelhos com o pacote de arenitos é marcado por uma camada de transição, de mais ou menos $60 \mathrm{~cm}$ de espessura, de intercalações centimétricas de arenitos finos creme a amarelo, com matriz argilosa com folhelhos e siltitos amarelos e avermelhados (nível D). Os arenitos (nível E) têm textura fina a muito fina, são inequigranulares com grãos predominantemente equidimensionais em amostra de mão, e conteúdos mineralógicos bastantes distintos quando diversos estratos arenosos são comparados. Apresentam como estrutura predominante estratificações plano-horizontais, subordinadamente marcas onduladas, e localmente podem ser observadas estratificações cruzadas planares e acanaladas. Dominantemente possuem matriz 


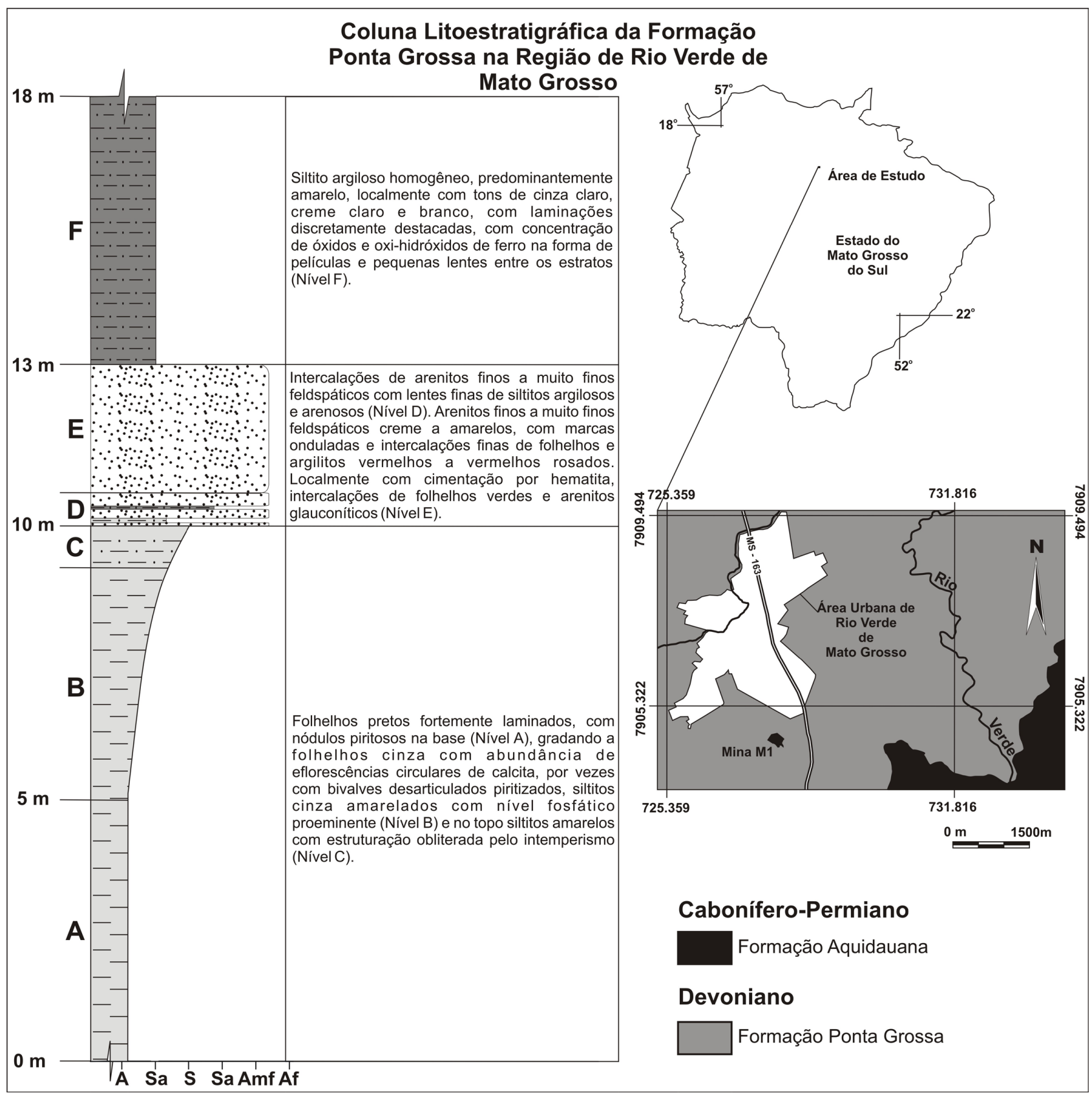

Figura 3. Coluna litoestratigráfica esquemática da Formação Ponta Grossa aflorante na região de Rio Verde de Mato Grosso, considerada indivisa. (A) Folhelhos pretos fortemente laminados com nódulos piritosos na base; (B) folhelhos cinza com abundância de eflorescências circulares de calcita e siltitos cinza amarelados com nível fosfático proeminente; (C) siltitos amarelos com estruturação obliterada pelo intemperismo; (D) intercalações de arenitos finos a muito finos feldspáticos com lentes finas de siltitos argilosos e arenosos; (E) Arenitos finos a muito finos feldspáticos, com marcas onduladas e intercalações finas de folhelhos e argilitos vermelhos a vermelhos rosados; (F) siltito argiloso homogêneo, predominantemente amarelo, com laminações discretamente destacadas e concentrações de óxidos e hidróxidos de ferro na forma de películas e pequenas lentes entre os estratos.

argilosa, mas foram encontrados níveis cimentados por carbonatos, cimentados por hematita, por limonita e goethita, ou aparentemente silicificados. Em geral apresentam cor creme, mas podem apresentar cor preta, marrom-café, vermelha, rosada, amarela, branca ou verde-pálido.
Os níveis mais espessos de arenitos apresentam diversas heterogeneidades e pequenas intercalações lenticulares ou níveis argilosos vermelho-rosado, além de níveis glauconíticos, níveis dominantemente micáceos e níveis intensamente ferruginizados (nível E). 


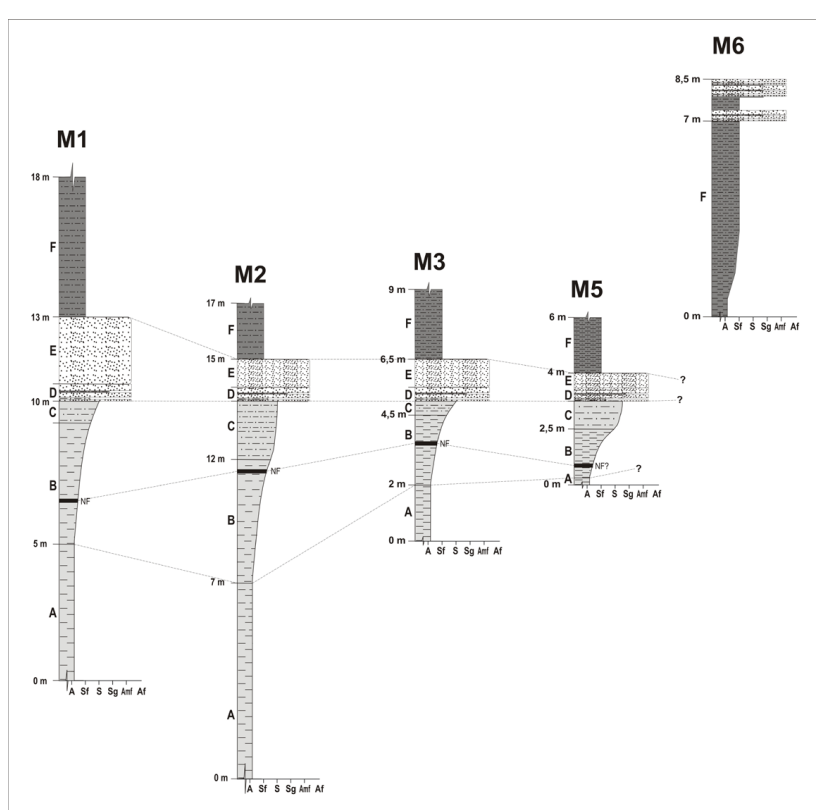

Figura 4. Seções colunares das exposições de rochas descritas em frentes de lavra nos municípios de Rio Verde de Mato Grosso e Coxim, mostrando a correlação entre os níveis aflorantes nas diversas localidades visitadas. Neste trabalho são apresentados resultados de análises petrográficas realizadas em todos os níveis (de A-F) e de análises químicas realizadas apenas nos níveis pelíticos (A, B, C e F).

Sobre o pacote de arenitos são encontrados siltitos argilosos e argilitos amarelos intensamente intemperizados e localmente solos residuais, areno-argilosos e/ou coberturas lateríticas com uma ou duas fases de goethitização reconhecidas (nível F). As litologias observadas na área de estudo (níveis A a F) estão descritas detalhadamente em Montibeller e Zanardo (2014a, 2014b) e Montibeller (2015).

Um morro alongado com orientação NW a WNW localizado logo a leste da mina M1 (cerca de $250 \mathrm{~m}$ ) é sustentado por pacotes decimétricos a métricos de arenitos finos ricos em bioturbação, que formam uma sequência com cerca de $10 \mathrm{~m}$ de espessura. O topo desta elevação está em cota cerca de $30 \mathrm{~m}$ acima do nível de arenito observado na mina $\mathrm{M} 1$, fato que permite estimar que o nível $\mathrm{F}$ atinja pelo menos $20 \mathrm{~m}$ de espessura.

De acordo com as descrições presentes na literatura (por exemplo, Lange e Petri, 1967; Petri, 1948 apud Assine et al., 1994; Correa et al., 1976; as feições texturais e o conteúdo mineralógico dos folhelhos da base da região estudada (níveis A, B e C) indicam correspondência destas rochas com aquelas atribuídas ao Membro Jaguariaíva da Formação Ponta Grossa. Contudo, considerando a posição estratigráfica desta sequência em relação às formações Furnas (subjacente) e Aquidauana (sobrejacente), e levando em consideração o padrão estrutural da região, a parte aflorante desta unidade apresenta algumas características semelhantes às descritas na literatura para a Série Chapada, o que permitiria inferir que se trata da porção de topo (Membro São Domingos). Entretanto, devido às espessuras das sucessões sedimentares, à mineralogia determinada, à escassez de fósseis e às alternâncias entre fácies, a subdivisão torna-se arbitrária, sendo recomendado considerar esta sucessão como "Formação Ponta Grossa Indivisa".

\section{PETROGRAFIA DOS SEDIMENTOS DA FORMAÇÃO PONTA GROSSA}

Os folhelhos cinza-escuros a pretos (nível A) da base da sequência estratigráfica são constituídos principalmente por filossilicatos diversos $( \pm 65 \%)$, carbonato (siderita) $( \pm 20 \%)$, quartzo e feldspato detríticos (predominantemente microclínio, com raro plagioclásio) $( \pm 10 \%)$, com presença de óxidos/hidróxidos de ferro $( \pm 5 \%)$ e traços de outros minerais detríticos (turmalina, zircão, rutilo). Os filossilicatos presentes são caulinita, illita, muscovita e biotita. A massa de filossilicatos finos apresenta coloração esverdeada, sugerindo a presença de delgadas palhetas de clorita e/ou a presença de ferro bivalente na constituição da illita/muscovita fina. Possuem estrutura fortemente anisotrópica, com bandamento composicional difuso e textura lutítica (granulometria média de aproximadamente $10 \mu \mathrm{m}$ ), composta por palhetas de mica detrítica e filossilicatos diagenéticos, intercrescidos com concentrações micríticas. Clastos granulares são relativamente raros e com dimensões menores que $50 \mu \mathrm{m}$. Petrograficamente, este litotipo é classificado como folhelho carbonático (siderítico).

Os folhelhos cinza (nível B) são compostos predominantemente por quartzo e feldspato detríticos (predominando microclínio) $( \pm 50 \%)$, filossilicatos detríticos $( \pm 20 \%)$, argilominerais neoformados $( \pm 15 \%)$, carbonato $( \pm 10 \%)$, opacos $( \pm 5 \%)$ e traços de outros minerais detríticos (turmalina, zircão e rutilo). Os filossilicatos são caulinita, illita, muscovita e clorita. A estrutura da rocha é laminada, com anisotropia marcada pela alternância de lâminas mais ricas em minerais granulares (quartzo e feldspato) e lâminas mais ricas em filossilicatos orientados. A textura varia de lutítica a psamítica de granulação argila a silte. Em petrografia, a rocha pode ser classificada como intercalações de folhelhos e siltitos arcosianos.

Petrograficamente, a faixa fosfática que ocorre como uma camada compacta descontínua alojada nos folhelhos do nível $\mathrm{B}$ corresponde a uma massa anisotrópica microcristalina, constituída por fosfatos de cálcio (apatita, carbonato-fluorapatita, hidroxilapatita) $( \pm 60 \%)$, com delgadas palhetas de filossilicatos (muscovita) orientados $( \pm 15 \%)$ e diversos aglomerados aproximadamente esféricos de goethita e hematita $( \pm 15 \%)$. Em menores proporções ocorrem grãos de quartzo $( \pm 5 \%)$ e cimentação carbonática $( \pm 5 \%)$. 
Os arenitos (níveis D e E) representam uma série de tipos petrográficos, dentre os quais predominam os arenitos muito finos arcosianos e destacam-se aqueles que possuem cimentação por hematita e os arenitos glauconíticos.

Os arenitos muito finos predominantes são constituídos por: grãos de quartzo (54\%) subarredondados e subesféricos menores que $150 \mu \mathrm{m}$; grãos de feldspato detrítico $( \pm 35 \%)$ predominantemente microclínio e muito raramente plagioclásio sódico, com as mesmas dimensões do quartzo; micas detríticas $( \pm 5 \%)$, predominando muscovita e subordinadamente biotita, com tamanho até $500 \mu \mathrm{m}$ e média em torno de $200 \mu \mathrm{m}$; minerais opacos e hidróxidos de ferro $( \pm 5 \%)$ que podem ser grãos detríticos ou opacos pulverulentos intersticiais, além dos hidróxidos ocorrerem como películas cimentando parcialmente certas porções da rocha, principalmente nos planos das laminações; illita/clorita neoformadas $( \pm 1 \%)$, sobrecrescidas ao feldspato; traços de outros minerais detríticos (zircão, turmalina e rutilo). Este litotipo apresenta estrutura difusamente bandada a laminada, com anisotropia marcada pela orientação dos filossilicatos detríticos, e distribuição ligeiramente heterogênea dos hidróxidos e óxidos de ferro. A textura é psamítica com ótima seleção granulométrica, com os maiores clastos granulares raramente atingindo mais de $150 \mu \mathrm{m}$ de diâmetro e média ao redor de $60 \mu \mathrm{m}$, embora os grãos possuam baixo grau de arredondamento e baixa esfericidade. A seleção mineralógica também foi pobre, e a compactação eliminou grande parte da porosidade através de dissolução por pressão. Podem ser classificados como arenitos arcosianos muito finos.

Os níveis cimentados por hematita são compostos por: grãos de quartzo (53\%) menores que $150 \mu \mathrm{m}$; grãos de feldspato detrítico $( \pm 30 \%)$ com as mesmas dimensões do quartzo; minerais opacos $( \pm 10 \%)$, que se trata predominantemente de hematita, e ocorrem tanto como pequenos grãos detríticos irregulares, quanto como massas pulverulentas envolvendo os grãos detríticos; micas detríticas $( \pm 4 \%)$, predominando muscovita e aparecendo biotita e clorita subordinadas, com dimensões de até $350 \mu \mathrm{m}$; illita/sericita $( \pm 3 \%)$, com características tanto pré-deposicionais quanto diagenéticas; traços de outros minerais detríticos (zircão, turmalina e rutilo). A estrutura destas rochas é difusa, com alguns resquícios de laminação marcados pela presença de hematita intersticial, e a textura é psamítica, com a média granulométrica em torno de $80 \mu \mathrm{m}$.

Alguns arenitos arcosianos são verdes e, portanto, classificados como "glauconita arenitos arcosianos". Petrograficamente são muito semelhantes aos arenitos muito finos arcosianos mais frequentes, sendo que os únicos atributos diferenciados são: a estrutura praticamente isotrópica ou difusamente bandada em seção delgada; o aparecimento de $\pm 5 \%$ de filossilicatos verdes em seção delgada, fracamente pleocroicos, sugerindo tratar-se de glauconita modificada pela diagênese. $\mathrm{O}$ termo "glauconita" é utilizado para uma série ou um grupo de filossilicatos progressivamente enriquecidos em ferro, cujo termo puro é a glauconita (Velde, 2013) e a sua presença tem conotação genética, uma vez que é associada a ambientes marinhos. O filossilicato verde ("glauconita") aparenta corroer os feldspatos detríticos e se associa nitidamente aos óxidos e hidróxidos de ferro autígenos; entretanto, não foi possível diagnosticar precisamente o tipo de filossilicato através apenas da microscopia óptica, podendo tratar-se de illita contendo ferro bivalente e magnésio, oriunda de glauconita, ou mesmo formada durante a diagênese a partir de outros filossilicatos e feldspato.

\section{CARACTERÍSTICAS GEOQUÍMICAS DA FORMAÇÃO PONTA GROSSA}

Neste trabalho são apresentados apenas dados geoquímicos das rochas pelíticas atribuídas à Formação Ponta Grossa na região dos municípios de Rio Verde de Mato Grosso e Coxim (MS), correspondentes aos níveis A, B, C e F. Quimicamente, estes níveis não apresentam diferenças significativas entre si, não sendo possível estabelecer agrupamentos relacionados às suas respectivas posições estratigráficas. Os resultados das análises químicas são mostrados na Tabela 1.

Quimicamente, as rochas pelíticas da Formação Ponta Grossa são classificadas, de acordo com o diagrama de Herron (1988), predominantemente como folhelhos (Figura 5A), com apenas duas amostras com composição de folhelhos ferruginosos (pela presença sutilmente maior de Fe no perfil decorrente da presença de siderita e óxi-hidróxidos de ferro), e duas amostras ligeiramente mais maturas mineralogicamente, com composição química de "wackes" (pela presença levemente mais acentuada de quartzo em relação a argilominerais, decorrente da sedimentação).

Segundo o diagrama de Roser e Korsch (1988), os sedimentos que compõem as rochas pelíticas da Formação Ponta Grossa são derivados principalmente de rochas ígneas máficas e/ou intermediárias (Figura 5B), com duas amostras de proveniência ígnea félsica ou sedimentar quartzosa. A tendência de alinhamento das amostras no diagrama de Roser e Korsch (1988) é resultado das contribuições de quartzo e feldspato potássico progressivamente maiores à medida que se caminha em direção aos níveis psamíticos, com contribuição progressivamente menor de filossilicatos. O nível F, por sua vez, representa o início de um novo ciclo de afogamento, apresentando, portanto, maior dispersão dos dados geoquímicos.

A razão $\mathrm{SiO}_{2} / \mathrm{Al}_{2} \mathrm{O}_{3}$ (Pettijohn, 1963) varia entre 1,84 e 4,92 (predominando valores abaixo de 2,90 , com média de 2,98), que é uma característica considerada como resultante de ambientes tectonicamente quiescentes ou cratônicos (Weaver, 1989), nos quais há sujeição a reciclagem sedimentar, como comprovado pelo diagrama $\mathrm{Th} / \mathrm{Sc}$ versus $\mathrm{Zr} / \mathrm{Sc}$ (McLennan et al., 1993) (Figura 6A). Segundo 


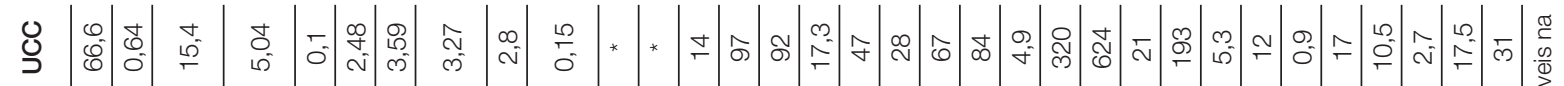

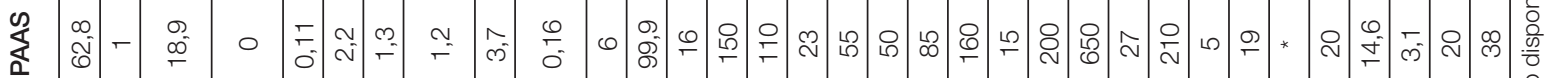

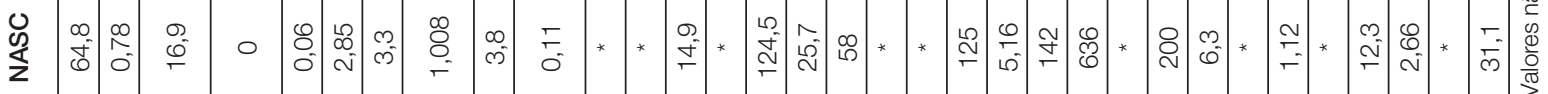

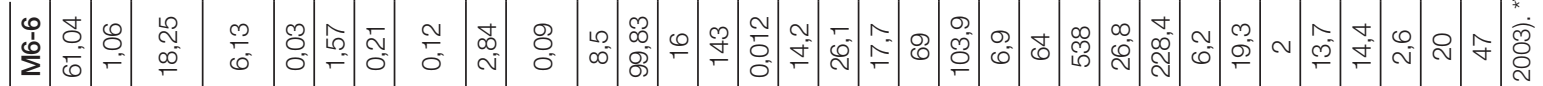

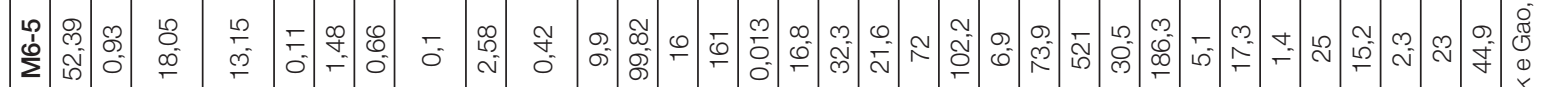

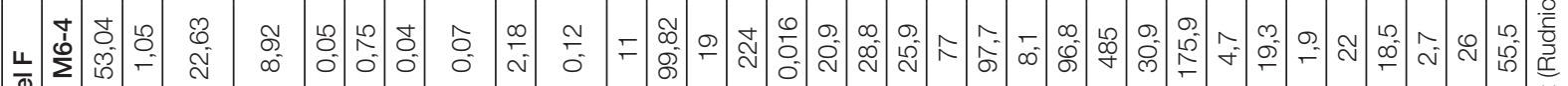

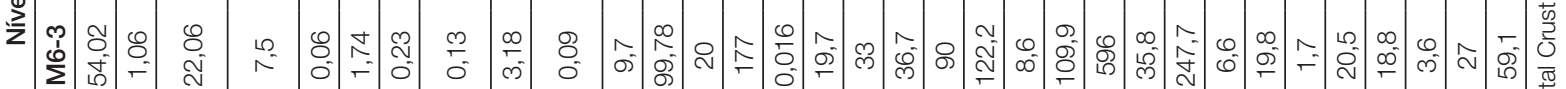

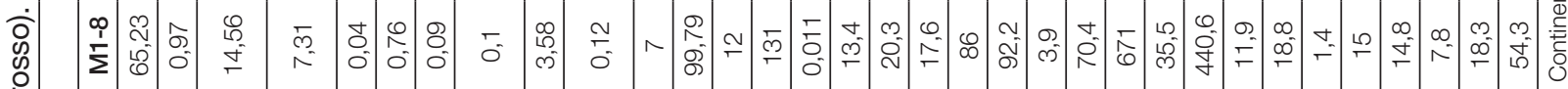

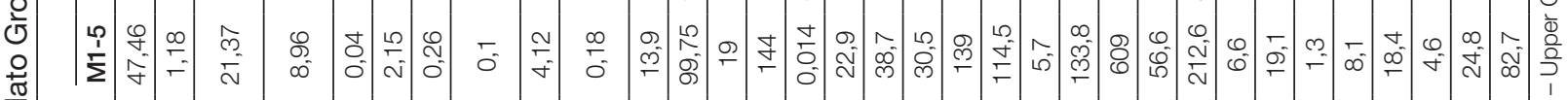

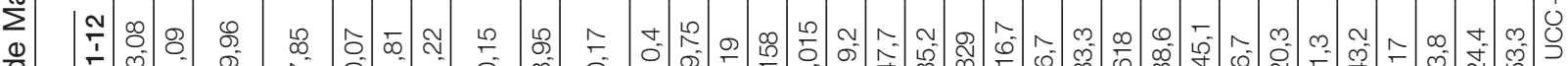

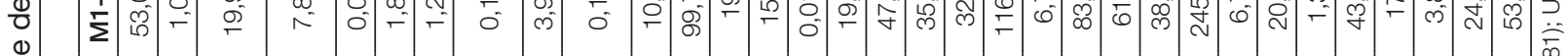

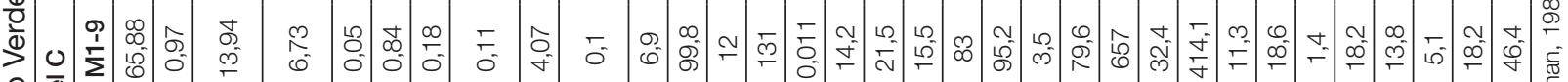

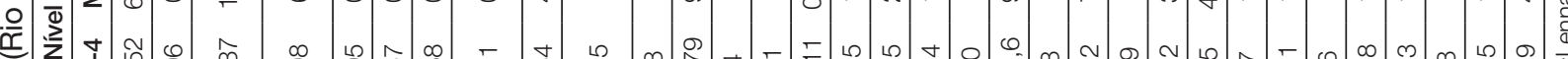

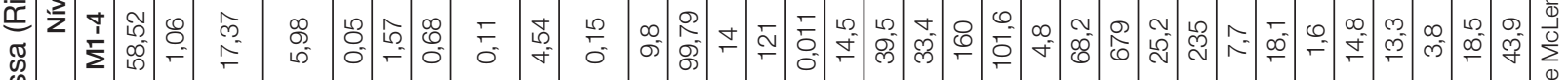

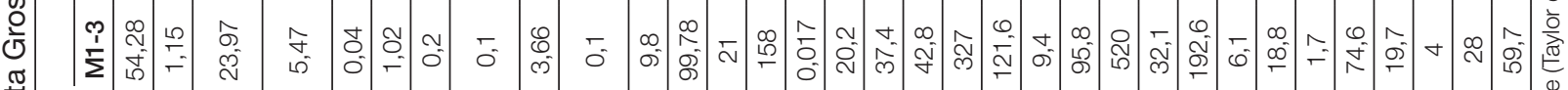

䒕 ᄋ

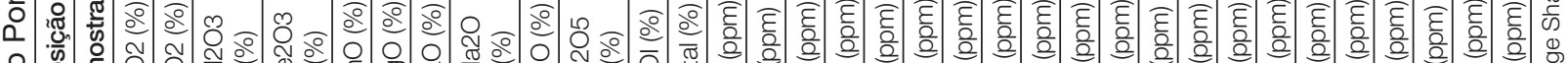

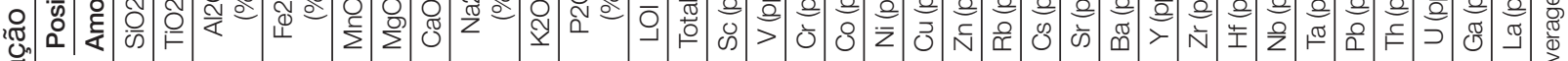

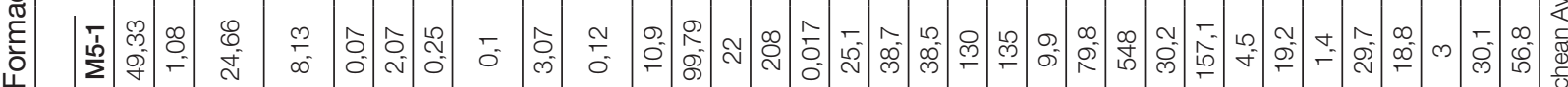

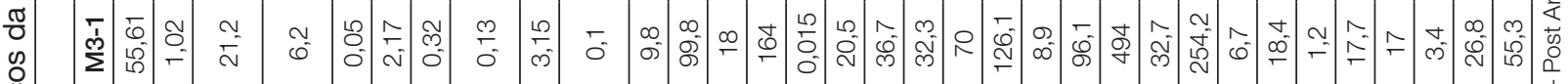

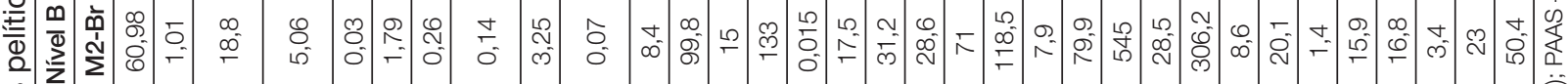

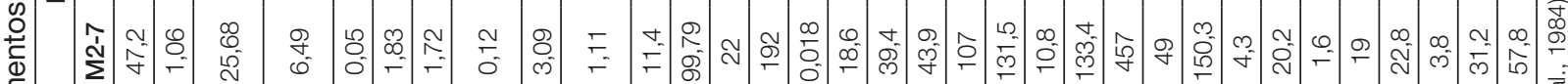

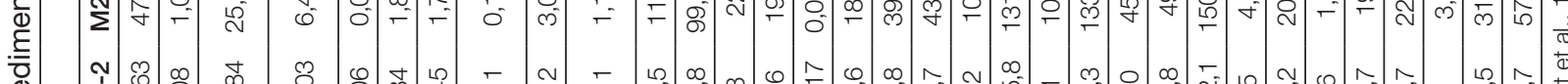

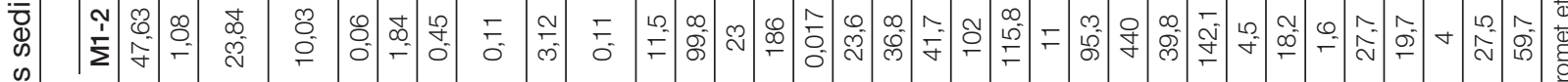

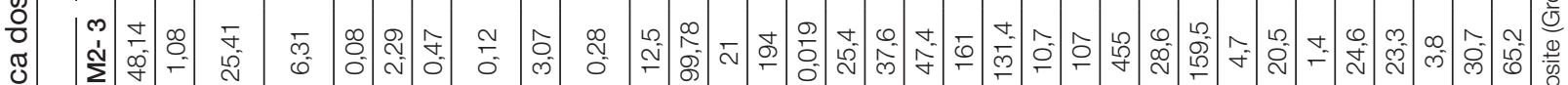

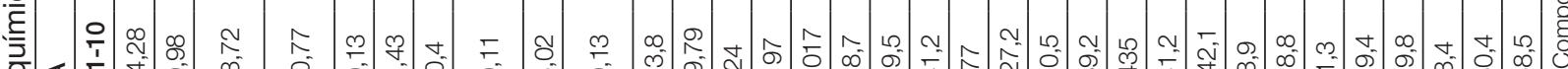

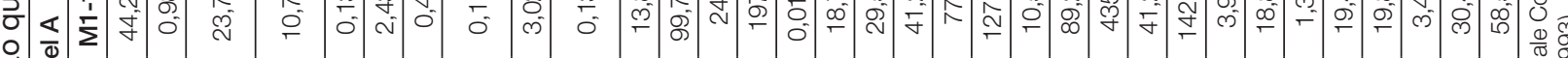

.

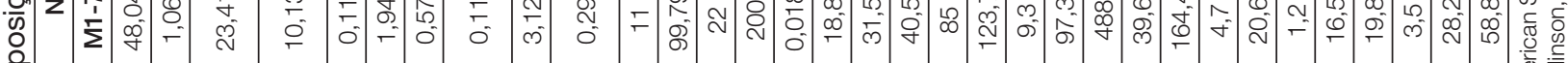

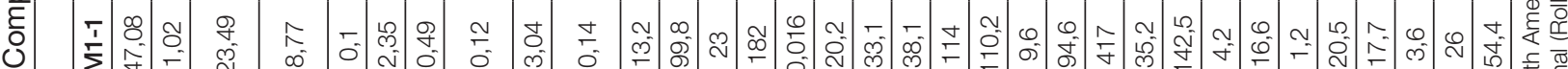

ฮ)

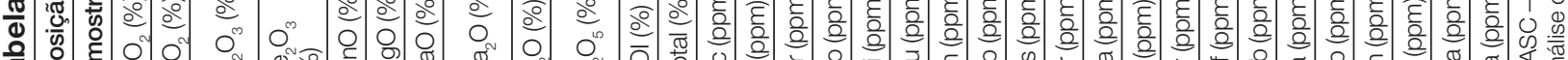
西 


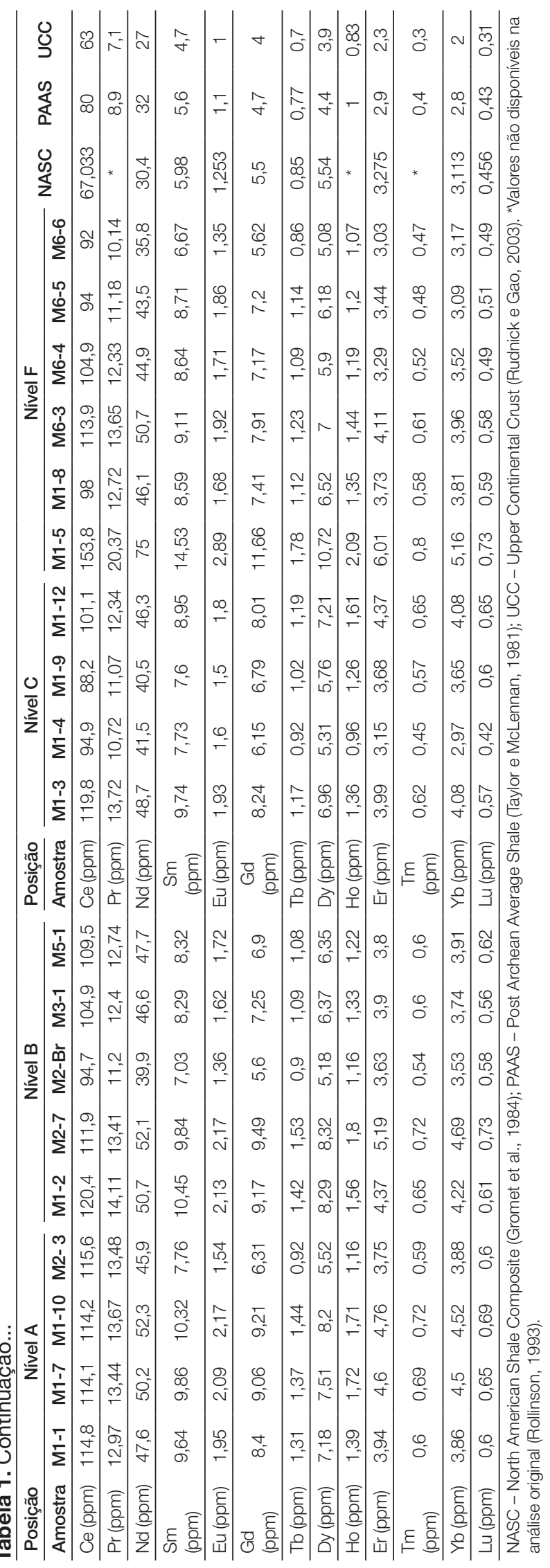


Armstrong-Altrin et al. (2015), razões $\mathrm{SiO}_{2} / \mathrm{Al}_{2} \mathrm{O}_{3}$ acima de 10 indicam alto grau de maturidade textural dos sedimentos, sendo que os valores correspondentes à Formação Ponta Grossa, portanto, representariam baixíssima maturidade textural. O Índice de Variação Composicional (Index of Compositional Variability - ICV) (Cox et al., 1995) das amostras da formação Ponta Grossa possui valores entre 0,49-1,05 (predominando valores entre 0,53 a 0,88), e a razão $\mathrm{K}_{2} \mathrm{O} / \mathrm{Al}_{2} \mathrm{O}_{3}$ varia entre 0,10 a 0,62 (predominando valores maiores que 0,33 ), indicando composição quimicamente matura e derivada de fonte submetida a intemperismo fraco (Figura 6B)
A)

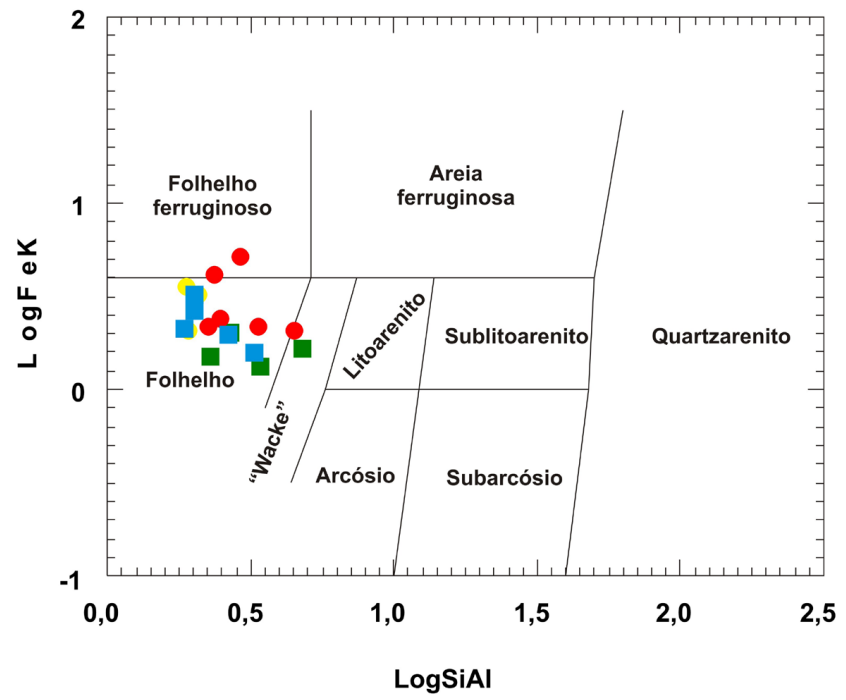

B)

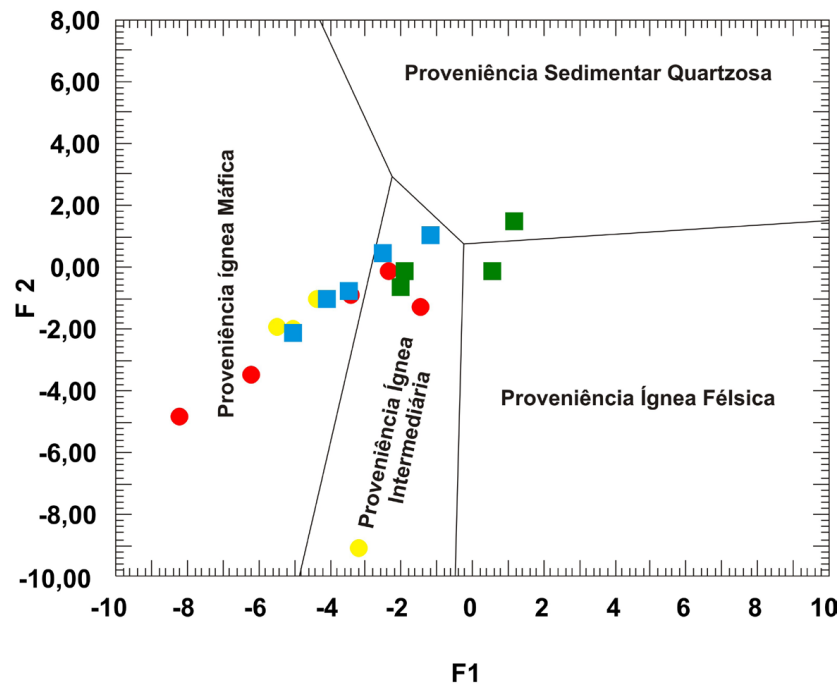

Figura 5. (A) Classificação química das amostras analisadas segundo diagrama de Herron (1988); (B) Diagrama para rocha fonte para as amostras analisadas (diagrama de Roser e Korsch, 1988). $\mathrm{F} 1=30,683 \mathrm{TiO}_{2} / \mathrm{Al}_{2} \mathrm{O}_{3}-12,541 \mathrm{Fe} \mathrm{O}_{3} \mathrm{~T} / \mathrm{Al}_{2} \mathrm{O}_{3}+$ $7,329 \mathrm{MgO} / \mathrm{Al}_{2} \mathrm{O}_{3}+12,031 \mathrm{Na}_{2} \mathrm{O} / \mathrm{Al}_{2} \mathrm{O}_{3}+35,402 \mathrm{~K}_{2} \mathrm{O} / \mathrm{Al}_{2} \mathrm{O}_{3}-6,382 ; \mathrm{F} 2=56,5 \mathrm{TiO}_{2} / \mathrm{Al}_{2} \mathrm{O}_{3}-10,879 \mathrm{Fe}_{2} \mathrm{O}_{3} \mathrm{~T}^{\mathrm{Al}} \mathrm{Al}_{2} \mathrm{O}_{3}+30,875$ $\mathrm{MgO} / \mathrm{Al}_{2} \mathrm{O}_{3}-5,404 \mathrm{Na}_{2} \mathrm{O} / \mathrm{Al}_{2} \mathrm{O}_{3}+11,112 \mathrm{~K}_{2} \mathrm{O} / \mathrm{Al}_{2} \mathrm{O}_{3}-3,89$.

A)

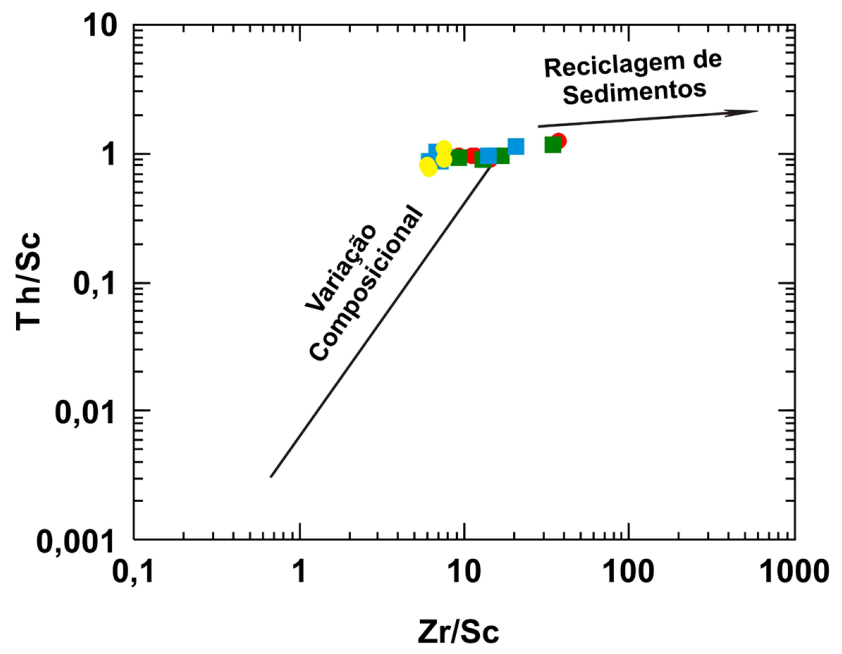

B)

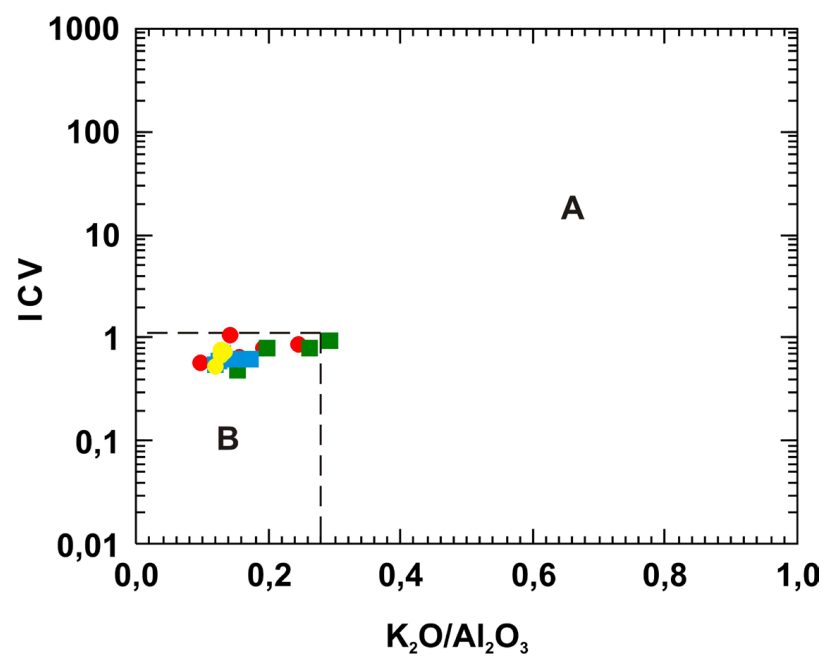

Nível A $\quad$ Nível B $\quad$ Nível C $\bigcirc$ Nível F

Figura 6. (A) Diagrama do tipo Th/Sc versus Zr/Sc para avaliação da ocorrência de reciclagem sedimentar (McLennan et al., 1993); (B) Índice de Variação Composicional (Index of Compositional Variability - ICV) e a razão $\mathrm{K}_{2} \mathrm{O}_{/} \mathrm{Al}_{2} \mathrm{O}_{3}$. Modificado de Cox et al. (1995). A - sedimentos quimicamente imaturos; B - sedimentos quimicamente maturos. 
O CIA (Chemical Index of Alteration, Nesbitt e Young, 1982) das amostras analisadas varia entre 72,5 e 90,9 (média de 84,7 ), predominando valores acima de 80 , sistematicamente maiores que o valor de CIA do NASC (CIA 58, Gromet et al., 1984), o que sugere intenso intemperismo químico na área fonte. Neste estudo, os valores de $\mathrm{CaO}$ foram corrigidos utilizando o método de McLennan et al. (1993) para cálculo do $\mathrm{CaO} *$. Também são utilizadas razões $\mathrm{K}_{2} \mathrm{O} / \mathrm{Na}_{2} \mathrm{O}$ e $\mathrm{Al}_{2} \mathrm{O}_{3} / \mathrm{Na}_{2} \mathrm{O}$ (McLennan e Taylor, 1991) para avaliar a intensidade do intemperismo químico na bacia, sendo que valores $\mathrm{Al}_{2} \mathrm{O}_{3} / \mathrm{Na}_{2} \mathrm{O}$ menores do que 3 indicam forte atuação do intemperismo químico (Armstrong-Altrin et al., 2015). As amostras da Formação Ponta Grossa possuem altas razões $\mathrm{Al}_{2} \mathrm{O}_{3} / \mathrm{Na}_{2} \mathrm{O}$ (de 118,58 a 565,75), predominando valores abaixo de 250 , enquanto as razões $\mathrm{K}_{2} \mathrm{O} / \mathrm{Na}_{2} \mathrm{O}$ variam entre 23,2 e 41,3 (média de 29,6), predominando valores abaixo de 30. Estas razões elevadas são, entretanto, resultantes da pequena proporção de $\mathrm{Na}_{2} \mathrm{O}$ nestes sedimentos, uma vez que há pouca ou nenhuma ocorrência de plagioclásio nas amostras analisadas, resultando em alto conteúdo em filossilicatos e feldspato potássico. Este fato permite inferir que houve processo de segregação eficiente do plagioclásio durante a erosão e o transporte dos sedimentos, refletindo atuação seletiva do intemperismo químico, ou que as rochas fontes se tratavam primariamente de rochas pobres em $\mathrm{Na}_{2} \mathrm{O}$, o que implicaria numa configuração crustal pouco comum.

$\mathrm{O}$ teor de $\mathrm{SiO}_{2}$ dos sedimentos da Formação Ponta Grossa analisados varia entre 44,28 e 65,88\%. Os teores de $\mathrm{Al}_{2} \mathrm{O}_{3}, \mathrm{Fe}_{2} \mathrm{O}_{3}, \mathrm{MgO}$ e $\mathrm{CaO}$ variam entre 13,94 e $25,68 \%$, 5,06 e $13,15 \%, 0,75$ e $2,43 \%$ e 0,04 e $1,72 \%$ respectivamente. $\mathrm{O}$ teor de $\mathrm{Na}_{2} \mathrm{O}$ varia entre 0,07 e $0,15 \%$, o de $\mathrm{K}_{2} \mathrm{O}$ varia entre 2,18 e $4,54 \%$ e o de $\mathrm{TiO}_{2}$ varia entre 0,93 e 1,18\%. Os teores de $\mathrm{P}_{2} \mathrm{O}_{5}$ e $\mathrm{MnO}$ variam de 0,07 a 1,11 e 0,03 a 0,13 respectivamente. Nos diagramas binários observam-se fortes correlações negativas entre $\mathrm{Al}_{2} \mathrm{O}_{3}$ e fracas correlações negativas entre $\mathrm{TiO}_{2}, \mathrm{Fe}_{2} \mathrm{O}_{3 \mathrm{~T}}, \mathrm{MnO}, \mathrm{MgO}$ e $\mathrm{CaO}$ em relação
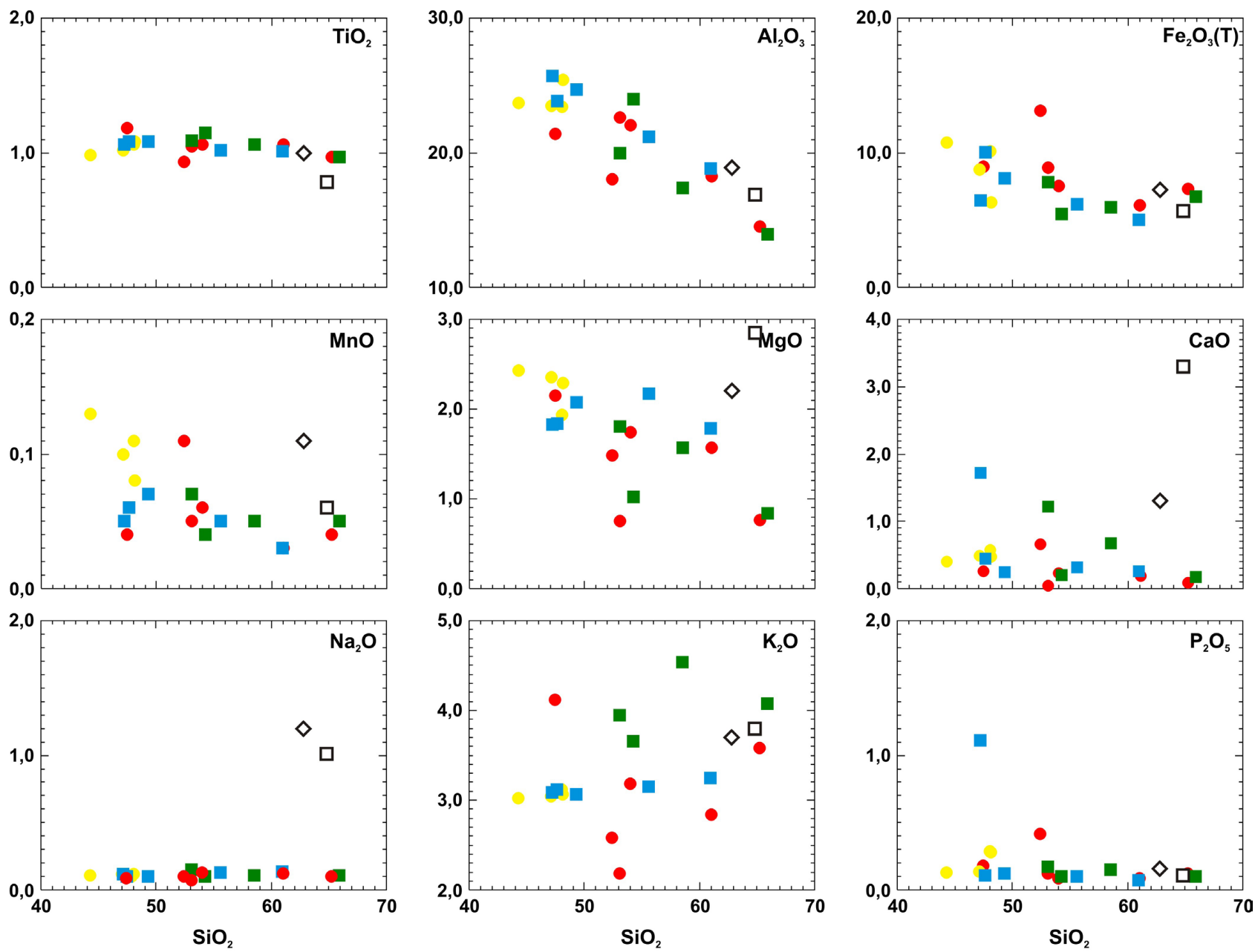

Nível A Nível B $\quad$ Nível C $\bullet$ Nível F

Figura 7. Diagramas binários de elementos maiores versus $\mathrm{SiO}_{2}$, mostrando a variação da composição das amostras estudadas. Quadrado branco: NASC; Losango branco: PASS. 

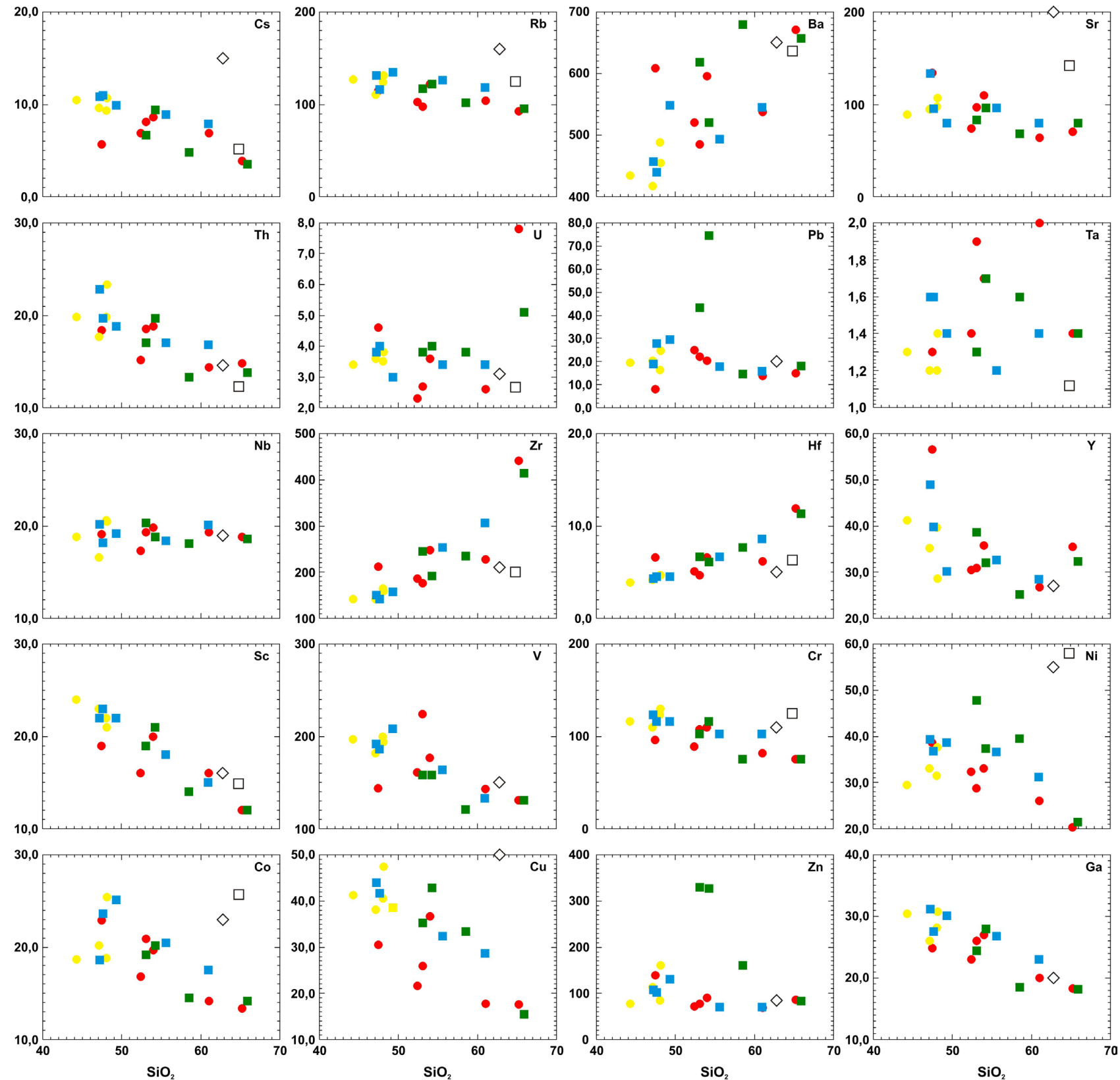

Nível A
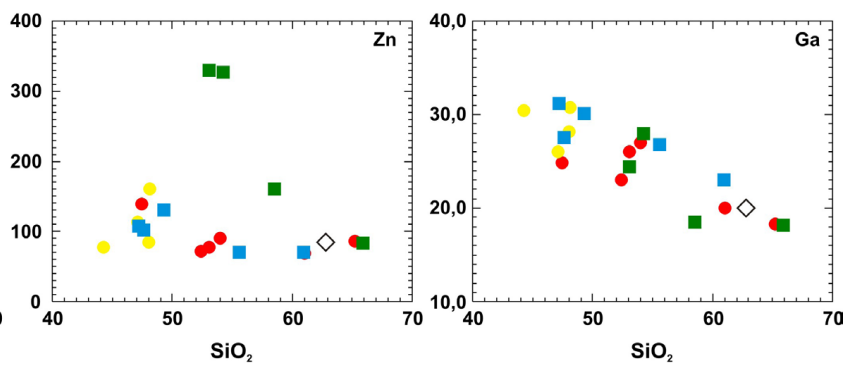

Figura 8. Diagramas binários de elementos menores e traço versus $\mathrm{SiO}_{2}$, mostrando a variação da composição das amostras estudadas. Quadrado branco: NASC; Losango branco: PAAS.

ao $\mathrm{SiO}_{2}$, não se observando correlações entre $\mathrm{Na}_{2} \mathrm{O}, \mathrm{K}_{2} \mathrm{O}$ e $\mathrm{P}_{2} \mathrm{O}_{5}$ (Figura 7). Em relação aos elementos menores e traços versus $\mathrm{SiO}_{2}$ (Figura 8), as amostras da Formação Ponta Grossa possuem correlação negativa em relação a Cs, Sr, Th, Sc, V, Cr, Co e Ga, mostrando correlações positivas para $\mathrm{Ba}, \mathrm{Zr}$ e Hf. Os teores de elementos maiores, menores e traços não apresentam diferenças significativas entre os níveis A, B, C e F da Formação Ponta Grossa em relação aos teores de $\mathrm{SiO}_{2}$, indicando que a natureza destes sedimentos permaneceu a mesma durante a deposição de todo o pacote analisado. A distribuição dos elementos maiores, menores e traços para as amostras analisadas não permite diferenciar grupos distintos, apenas correlações negativas e/ou positivas em relação ao $\mathrm{SiO}_{2}$ refletindo diretamente a proporção entre as principais fases minerais (proporções de argilominerais, feldspatos e quartzo presentes nas amostras).

Nos diagramas binários de elementos maiores e traços, as amostras são comparadas com as médias mundiais para sedimentos NASC (Gromet et al., 1984) e PAAS (Taylor e McLennan, 1981). Comparativamente com as médias 
mundiais, os sedimentos da Formação Ponta Grossa possuem teores maiores de $\mathrm{Al}_{2} \mathrm{O}_{3}$ e possuem menores teores de $\mathrm{MgO}$, $\mathrm{CaO}$ e $\mathrm{Na}_{2} \mathrm{O}$. Os teores de $\mathrm{TiO}_{2}, \mathrm{Fe}_{2} \mathrm{O}_{3 \mathrm{~T}}, \mathrm{MnO}, \mathrm{K}_{2} \mathrm{O}$ e $\mathrm{P}_{2} \mathrm{O}_{5}$ são semelhantes (Figura 7). Em relação aos elementos traços, possuem menores teores em $\mathrm{Ba}, \mathrm{Sr}, \mathrm{Ni}$, $\mathrm{Co}$ e $\mathrm{Cu}$, e em parte são mais enriquecidas em Th, Ta, Y, Sc, Ga e U, e possuem teores semelhantes em $\mathrm{Cs}, \mathrm{Rb}, \mathrm{Pb}, \mathrm{Nb}, \mathrm{Zr}, \mathrm{Hf}$, $\mathrm{V}, \mathrm{Cr}$ e Zn (Figura 8).

Em relação aos elementos terras raras, as amostras dos sedimentos da Formação Ponta Grossa, quando comparados com os teores das médias mundiais para sedimentos NASC (Gromet et al., 1984) e PAAS (Taylor e McLennan, 1981), são mais enriquecidos $\left(\Sigma \mathrm{ETR}_{\mathrm{NASC}}=154,50, \Sigma \mathrm{ETR}_{\mathrm{PAAS}}=183,00\right.$, $\Sigma \mathrm{ETR}_{\mathrm{Fm} \mathrm{Ponta} \mathrm{Grossa}}=144,85-388,24$, média $\left.=246,78\right)$. O padrão de distribuição de ETR da Formação Ponta Grossa, quando normalizados pela crosta continental superior (Rudnick e Gao, 2003), é sub-horizontal, mostrando leves empobrecimentos e enriquecimentos em ETRL em relação $\operatorname{a\operatorname {ETRP}}\left(\mathrm{La}_{(\mathrm{N})} / \mathrm{Lu}_{(\mathrm{N})}=0,55-1,13, \mathrm{La}_{(\mathrm{N})} / \mathrm{Eu}_{(\mathrm{N})}=0,48-1,37\right.$, $\left.\mathrm{Gd}_{(\mathbb{N})} / \mathrm{Lu}_{(\mathrm{N})}=0,75-1,44\right)$, não exibindo anomalias de európio $\left(\mathrm{Eu}^{*}=0,87-1,02\right)$ (Figura 9A).

Nos diagramas multielementares para HFSE ( $\mathrm{Ta}, \mathrm{Nb}$, Hf, Ti, Y), LILE (Cs, Rb, Ba, K, Th, U, Sr), ETR e P, Sc, V, $\mathrm{Cr}, \mathrm{Co}, \mathrm{Ni}, \mathrm{Cu}, \mathrm{Zn}$ e $\mathrm{Ga}$, normalizados pela crosta superior (Rudnick e Gao, 2003) (Figura 9B), o padrão de distribuição mostra que, em relação à crosta superior, os sedimentos da Formação Ponta Grossa são levemente empobrecidos em $\mathrm{Sr}$, Ba e Ni, e levemente enriquecidos em Th, Ta, Nb, Ti, Y, $\mathrm{V}, \mathrm{Zn}$ e Ga. Também mostram tendência de enriquecimento em Cs, K, U e Sc, e distribuições semelhantes nos outros elementos.
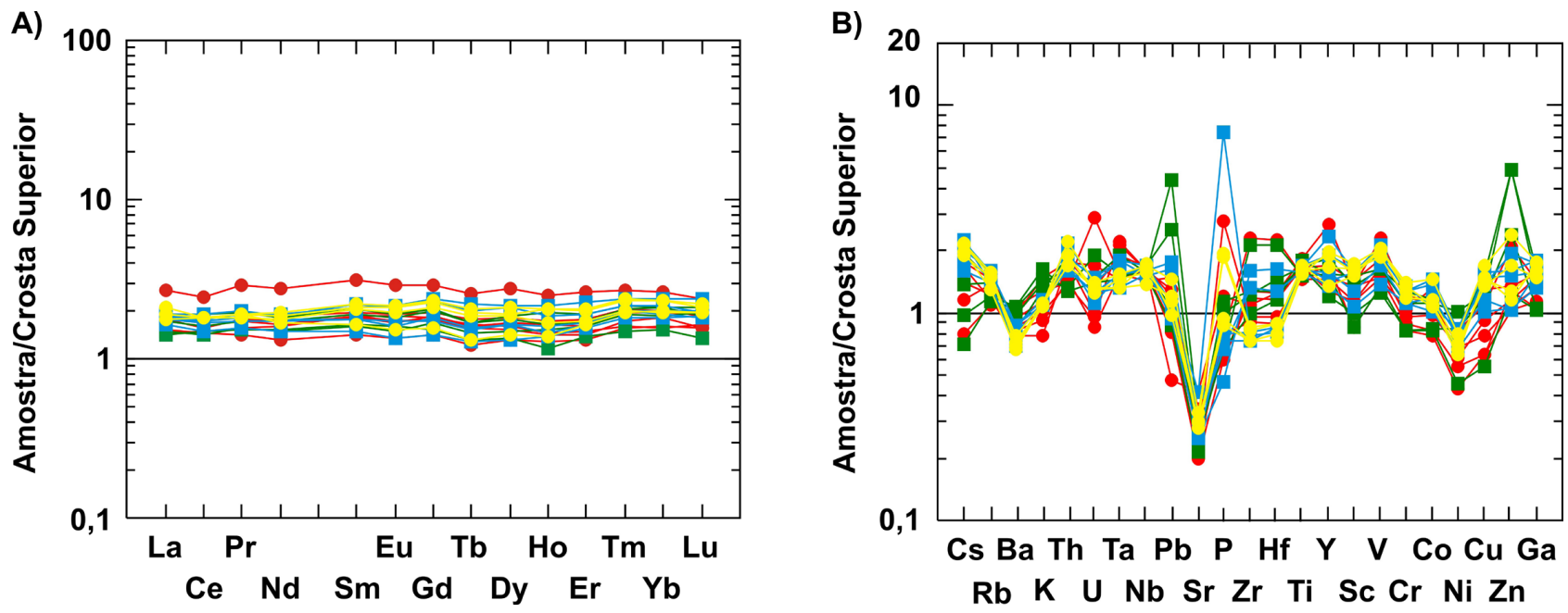

\section{Nível A Nível B $\quad$ Nível C O Nível F}

Figura 9. (A) Padrão de distribuição de ETR normalizados pela crosta continental superior (Rudnick e Gao, 2003) para as amostras analisadas; (B) Padrão de distribuição de elementos menores e traços normalizados pela crosta continental superior (Rudnick e Gao, 2003) para as amostras analisadas. 
A)

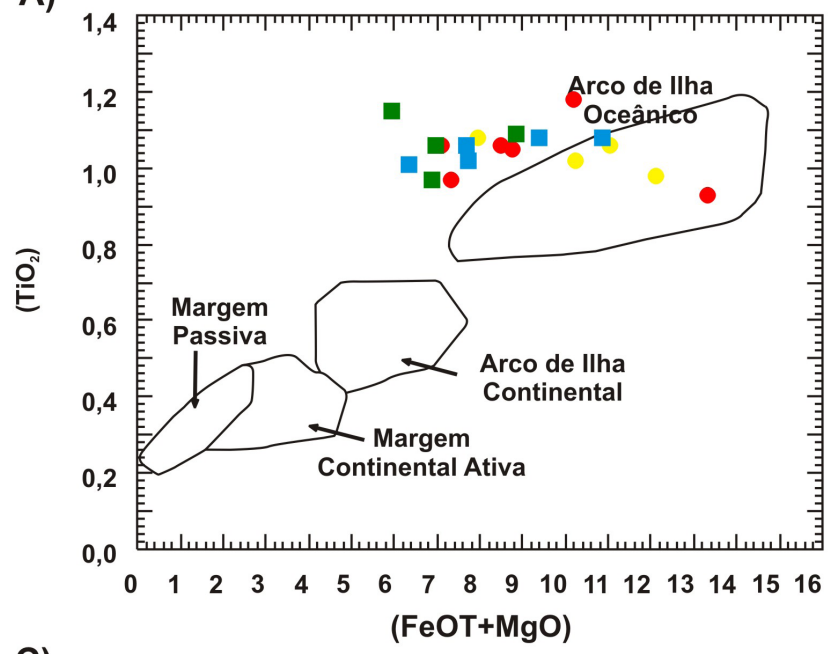

C)

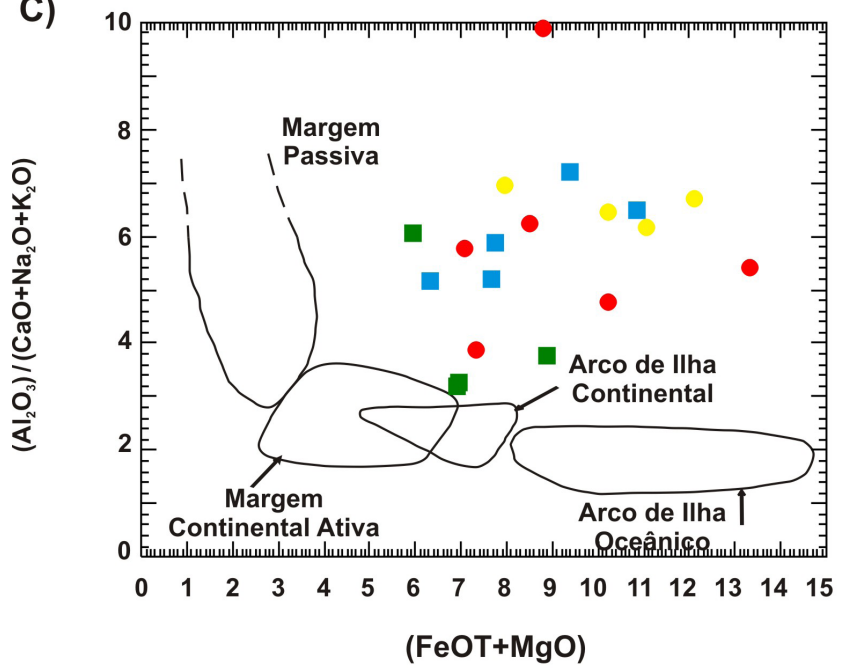

B)

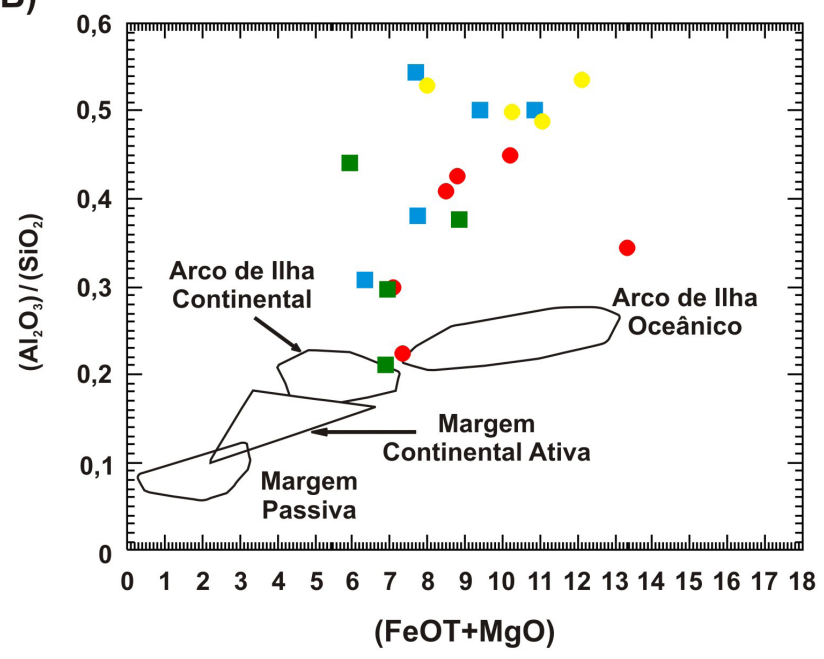

D)

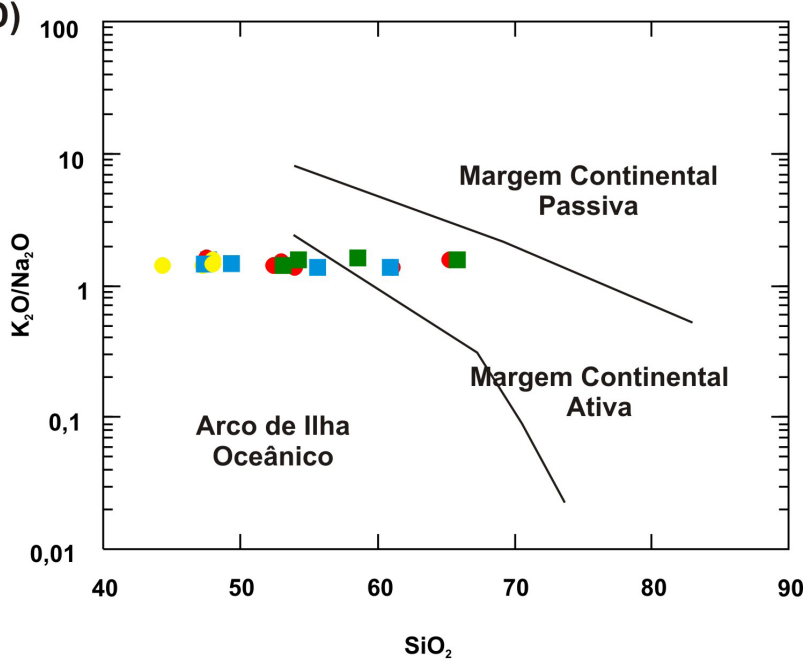

Nível C Nível F

Figura 10. Diagramas discriminantes para as rochas analisadas. (A-C) Bhatia (1983); (D) Roser e Korsch (1988).

discriminantes $\left(\mathrm{F} 3=0,303-0,0447 \mathrm{SiO}_{2}-0,972 \mathrm{TiO}_{2}+\right.$ $0,008 \mathrm{Al}_{2} \mathrm{O}_{3}-0,267 \mathrm{Fe}_{2} \mathrm{O}_{3}+0,208 \mathrm{FeO}-3,082 \mathrm{MnO}+$ $0,14 \mathrm{MgO}+0,195 \mathrm{CaO}+0,719 \mathrm{Na} 2 \mathrm{O}-0,032 \mathrm{~K} 2 \mathrm{O}+7,51 \mathrm{P}_{2} \mathrm{O}_{5}$; $\mathrm{F} 4=43,57-0,421 \mathrm{SiO}_{2}+1,988 \mathrm{TiO}_{2}-0,526 \mathrm{Al}_{2} \mathrm{O}_{3}-0,551 \mathrm{Fe}_{2} \mathrm{O}_{3}-$ $1,61 \mathrm{FeO}+2,72 \mathrm{MnO}+0,881 \mathrm{MgO}-0,907 \mathrm{CaO}-0,177 \mathrm{Na}_{2} \mathrm{O}-$ $1,84 \mathrm{~K}_{2} \mathrm{O}+7,244 \mathrm{P}_{2} \mathrm{O}_{5}$ ) parametrizam a influência dos elementos maiores em diferentes ambientes tectônicos. Neste diagrama, as amostras da Formação Ponta Grossa encontram-se predominantemente distribuídas no campo das rochas depositadas em margem passiva, assim como demonstrado no diagrama binário $\mathrm{La} / \mathrm{Y}$ versus $\mathrm{Sc} / \mathrm{Cr}$ (Bhatia e Crook, 1986). Bhatia e Crook (1986), por sua vez, propuseram também a utilização de diagramas binários do tipo $\mathrm{Ti} / \mathrm{Zr}$ versus $\mathrm{La} / \mathrm{Sc}$, e de diagramas ternários do tipo La-Th-Sc, Th-Co-Zr/10 e Th-Sc-Zr/10 como ferramentas para caracterizar a proveniência de sedimentos e para ajudar a determinar a natureza da margem continental ou da bacia oceânica, por considerarem que esses elementos apresentam comportamento menos móvel em bacias sedimentares. Nestes diagramas, as rochas pelíticas da Formação Ponta Grossa apresentam comportamentos variados, principalmente em decorrência da natureza da rocha fonte. No diagrama $\mathrm{Ti} / \mathrm{Zr}$ versus $\mathrm{La} / \mathrm{Sc}$ (Figura 11C), por exemplo, as amostras apresentam um trend entre arcos de ilha oceânicos, arcos de ilha continentais e margens continentais ativas, principalmente por conta da razão $\mathrm{Ti} / \mathrm{Zr}$, sendo que Ti é mais enriquecido em rochas máficas a intermediárias do que em rochas ácidas, e $\mathrm{Zr}$ tem comportamento inverso. O La, por sua vez, tem afinidade com rochas ígneas félsicas, enquanto o $\mathrm{Sc}$ tem maior afinidade com rochas básicas, resultado que rochas sedimentares derivadas de rochas básicas possuem razões $\mathrm{La} / \mathrm{Sc}$ baixas. No caso do $\mathrm{Zr}$, se admitirmos que em rochas 
A)

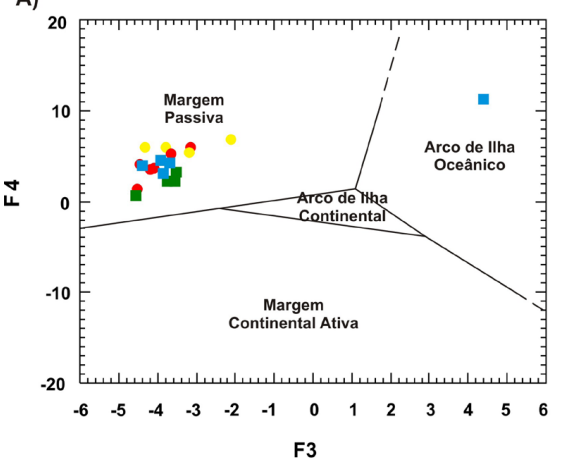

D)

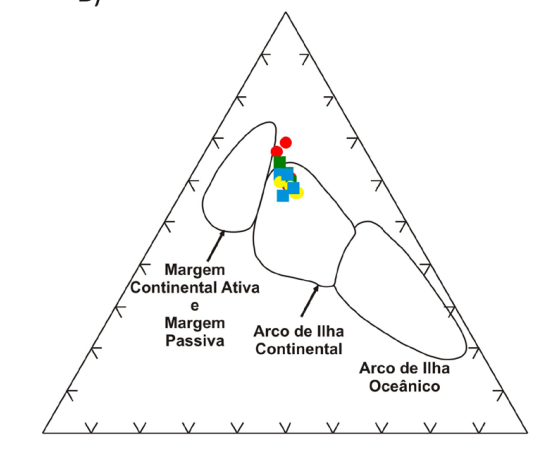

Th

sc
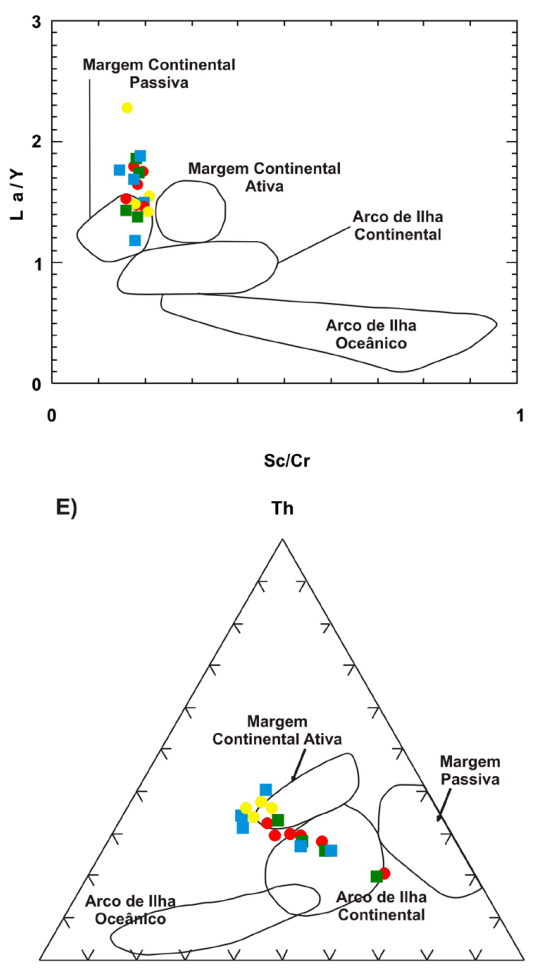

C)

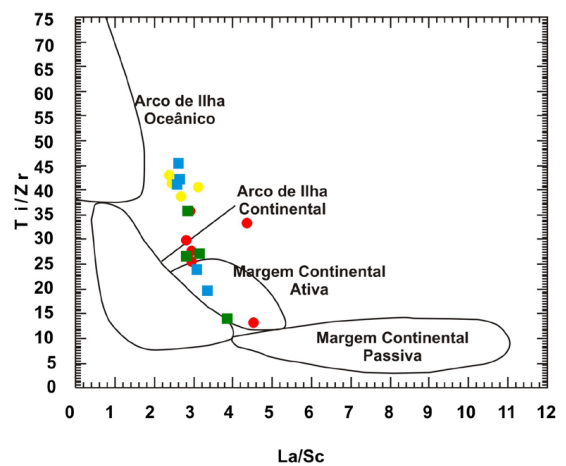

F)

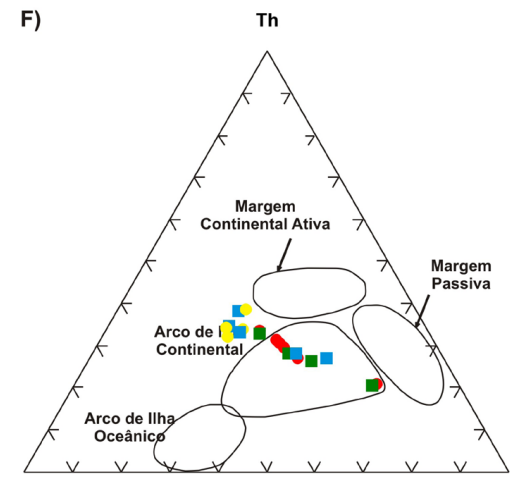

Co

- Nível A Nível B a Nível C Nível F

Figura 11. Diagramas discriminantes para as rochas analisadas. (A) Roser e Korsch (1988); (B-F) Bhatia e Crook (1986). $\mathrm{F} 3=0,303-0,0447 \mathrm{SiO}_{2}-0,972 \mathrm{TiO}_{2}+0,008 \mathrm{Al}_{2} \mathrm{O}_{3}-0,267 \mathrm{Fe}_{2} \mathrm{O}_{3}+0,208 \mathrm{FeO}-3,082 \mathrm{MnO}+0,14 \mathrm{MgO}+0,195 \mathrm{CaO}+0,719 \mathrm{Na}_{2} \mathrm{O}-$ $0,032 \mathrm{~K}_{2} \mathrm{O}+7,51 \mathrm{P}_{2} \mathrm{O}_{5} ; \mathrm{F} 4=43,57-0,421 \mathrm{SiO}_{2}+1,988 \mathrm{TiO}_{2}-0,526 \mathrm{Al}_{2} \mathrm{O}_{3}-0,551 \mathrm{Fe}_{2} \mathrm{O}_{3}-1,61 \mathrm{FeO}+2,72 \mathrm{MnO}+$ $0,881 \mathrm{MgO}-0,907 \mathrm{CaO}-0,177 \mathrm{Na}_{2} \mathrm{O}-1,84 \mathrm{~K}_{2} \mathrm{O}+7,244 \mathrm{P}_{2} \mathrm{O}_{5}$.

sedimentares o Zr provavelmente está associado à estrutura do zircão, sua concentração será devida à natureza e à energia do transporte dos grãos. Sendo assim, em sedimentos mineralogicamente imaturos, como é o caso dos folhelhos, a razão Ti/Zr refletirá muito provavelmente a concentração e/ou dispersão durante a atuação de processos sedimentares, associado à natureza da área fonte, e não às características químicas esperadas para determinados ambientes tectônicos. Nos diagramas ternários La-Th-Sc, Th-Co-Zr/10 e Th-Sc-Zr/10, entretanto, os elementos associados permitem a classificação dos ambientes das rochas fontes também como provenientes de arcos de ilhas oceânicos.

Desta forma, nos diagramas $\mathrm{F} 3$ versus $\mathrm{F} 4 \mathrm{e} \mathrm{La/Y}$ versus $\mathrm{Sc} / \mathrm{Cr}$, as amostras analisadas apresentam similaridades com sedimentos provenientes de ambiente de margem continental passiva (Figura 11A, B), enquanto nos diagramas Ti/Zr versus $\mathrm{La} / \mathrm{Sc}$ (Figura 11C), diagramas ternários do tipo La-Th-Sc, $\mathrm{Th}-\mathrm{Co}-\mathrm{Zr} / 10$ e Th-Sc-Zr/10 apresentam similaridades com rochas provenientes de arcos de ilhas continentais e margens continentais ativas (Figura 11D-F).

\section{CONCLUSÕES}

A composição química de rochas sedimentares terrígenas varia em função de diversos fatores, tais como área fonte (tipos litológicos, ambiente tectônico, etc.), intemperismo (relevo, clima, seleção físico-química, etc.), transporte (taxa de erosão, distância, etc.) e diagênese (profundidade de soterramento, gradientes geotérmicos e de pressão, etc.).

Diversos autores (Bathia, 1983, 1985; Bathia e Crook, 1986; Cox et al., 1995, etc.) propuseram uma série de diagramas discriminantes para ambientes de sedimentação, principalmente em relação à distinção entre ambientes de margem passiva e margem ativa. Entretanto, devido à complexidade que envolve a origem, transporte, sedimentação e diagênese de sedimentos, alguns autores têm questionado a eficiência desses diagramas (por exemplo, Floyd et al., 1991; McCann, 1991; Armstrong-Altrin e Verma, 2005; Ryan e Williams 2007, etc.). A maioria desses diagramas utiliza elementos maiores, uma vez que esses elementos tendem a indicar a composição química da rocha fonte. Entretanto, em função do grau de intemperismo, esses 
elementos deixam de ser bons indicadores de proveniência, sendo mais úteis para estimar o grau de intemperismo que atuou na rocha fonte. Dessa forma também foram propostos diagramas para proveniência e ambientes tectônicos, que utilizam elementos traços pouco móveis (Bathia e Crook, 1986). Em diagramas cujos elementos considerados representam a influência de processos de alteração e seleção na composição dos sedimentos, as rochas da Formação Ponta Grossa tendem a apresentar composição semelhante a rochas depositadas em ambientes de margem passiva, enquanto em diagramas cujos elementos considerados melhor representam a variabilidade química das rochas fontes, as amostras da Formação Ponta Grossa tendem a apresentar composição semelhante a rochas provenientes de arcos de ilhas continentais, e em menor proporção, ambientes de margens continental ativa e arcos de ilhas oceânicos. Entretanto, durante o Devoniano no Brasil, o contexto tectônico era de margem passiva. Dessa forma, embora a assinatura geoquímica possa sugerir ambiente deposicional de margem ativa para esses sedimentos, é mais provável que esses sedimentos tiveram como principal fonte rochas máficas e intermediárias formadas em margens ativas e/ ou arcos de ilhas continentais, erodidas e depositadas em margens passivas. A distribuição homogênea entre os elementos menores, traços e ETR, e principalmente em relação a elementos maiores (principalmente elementos móveis como $\mathrm{Na}$ e K), sugerem que a fonte dos sedimentos da Formação Ponta Grossa permaneceu constante durante a deposição de todo o pacote analisado, não ocorrendo mudanças significativas na composição química das rochas fontes.

Em relação às condições intempéricas às quais as rochas fontes da sequência pelítica da Formação Ponta Grossa analisada foram submetidas, têm-se bons indicadores químicos de que estas foram submetidas a intemperismo fraco, sendo esses sedimentos quimicamente maturos e texturalmente imaturos. O CIA e as razões $\mathrm{Al}_{2} \mathrm{O}_{3} / \mathrm{Na}_{2} \mathrm{O}$, embora apresentem situações conflitantes quanto ao intemperismo na área fonte, não podem ser utilizados como indicadores no caso das rochas da Formação Ponta Grossa analisadas, por estas apresentarem primariamente teores muito baixos de $\mathrm{Na}_{2} \mathrm{O}$ em relação aos teores de $\mathrm{CaO}$ e $\mathrm{K}_{2} \mathrm{O}$, sendo este fato relacionado a mecanismos de transporte, seleção e intemperismo que não podem ser elucidados através das relações composicionais destas rochas sedimentares.

\section{AGRADECIMENTOS}

Ao CNPq (processos 165168/2013-7 e 304535/2011-7) e FAPESP (processo 2013/04235-2).

\section{REFERÊNCIAS}

Amorosi, A., Centineo, M. C., Dinelli, E., Lucchini, F., Tateo, F. (2002). Geochemical and mineralogical variations as indicators of provenance changes in Late Quaternary deposits of SE Po Plain. Sedimentary Geology, 151, 273-292.

Armstrong-Altrin, J. S. (2009). Provenance of sands from Cazones, Acapulco, and Bahía Kino beaches, Mexíco. Revista Mexicana de Ciencias Geológicas, 26(3), 764-782.

Armstrong-Altrin, J. S., Machain-Castillo, M. L., RosalesHoz, L., Carranza-Edwards, A., Sanchez-Cabeza, J. A., RuízFernández, A. C. (2015). Provenance and depositional history of continental slope sediments in the Southwestern Gulf of Mexico unraveled by geochemical analysis. Continental Shelf Research, 95, 15-26.

Armstrong-Altrin, J. S., Verma, S. P. (2005). Critical evaluation of six tectonic setting discrimination diagrams using geochemical data of Neogene sediments from known tectonic settings. Sedimentary Geology, 177, 115-129.

Assine, M. L., Soares, P. C., Milani, E. J. (1994). Seqüências tectono-sedimentares mesopaleozóicas da Bacia do Paraná, sul do Brasil. Revista Brasileira de Geociencias, 24(2), 77-89.

Bakkiaraj, D., Nagendra, R., Nagarajan, R., ArmstrongAltrin, J. S. (2010). Geochemistry of sandstones from the Upper Cretaceous Sillakkudi Formation, Cauvery Basin, Southern India: implication for provenance. Journal of the Geological Society of India, 76, 453-467.

Bhatia, M. R. (1983). Plate tectonics and geochemical composition of sandstones. The Journal of Geology, 91(6), 611-627.

Bhatia, M. R. (1985). Composition and classification of paleozoic flysch mudrocks of eastern Australia: implications in provenance and tectonic setting interpretation. Sedimentary Geology, 41, 249-268.

Bhatia, M. R., Crook, K. A. W. (1986). Trace element characteristics of graywackes and tectonic setting discrimination of sedimentary basins. Contributions to Mineralogy and Petrology, 92, 181-193.

Bosetti, E. P., Grahn, Y., Horodyski, R. S., Mauller, P. M. (2012). The first recorded decline of the Malvinokaffric Devonian fauna in the Paraná Basin (southern Brazil) and its cause, taphonomic and fossil evidences. Journal of South American Earth Sciences, 37, 228-241.

Corrêa, J. A., Neto, C., Correia Filho, F. C. L., Scislewski, G., Cavallon, L. A., Cerqueira, N. L. S., Nogueira, V. L. (1976). Projeto Bodoquena: relatório final (Texto Integrado), v. 1, 356 p. Goiânia: MME/DNPM. 
Cox, R., Lowe, D. R., Cullers, R. L. (1995). The influence of sediment recycling and basement composition on evolution of mudrock chemistry in the southwestern United States. Geochimica et Cosmochimica Acta, 59(14), 2919-2940.

Cullers, R. L. (1994). The controls on the major and trace element variation of shales, siltstones, and sandstones of Pennsylvanian-Permian age from uplifted continental blocks in Colorado to platform sediment in Kansas, USA. Geochimica et Cosmochimica Acta, 58(22), 4955-4972.

Cullers, R. L. (1995). The controls on the major- and traceelement evolution of shales, siltstones and sandstones of Ordovician to Tertiary age in the Wet Mountains region, Colorado, U.S.A. Chemical Geology, 123, 107-131.

Cullers, R. L. (2000). The geochemistry of shales, siltstones and sandstones of Pennsylvanian-Permian age, Colorado, USA: implications for provenance and metamorphic studies. Lithos, 51, 181-203.

Cullers, R. L. (2002). Implications of elemental concentrations for provenance, redox conditions, and metamorphic studies of shales and limestones near Pueblo, CO, USA. Chemical Geology, 191, 305-327.

Evans, J. W. (1894). The geology of Matto Grosso (particularly the region drained by the Upper Paraguay). Quarterly Journal of the Geological Society, 50, 85-102.

Fatima, S., Khan, M. S. (2012). Petrographic and geochemical characteristics of Mesoproterozoic Kumbalgarh clastic rocks, NW Indian shield: implications for provenance, tectonic setting, and crustal evolution. International Geology Review, 54(10), 1113-1144.

Floyd, P. A., Shail, R., Leveridge, B. E., Franke, W. (1991). Geochemistry and provenance of Rhenohercynian synorogenic sandstones: implications for tectonic environment discrimination. Geological Society Special Publication, 57, 173-188.

Garver, J. I., Royce, P. R., Smick, T. A. (1996). Chromium and Nickel in shale of the Taconic Foreland: a case study for the provenance of fine-grained sediments with and ultramafic source. Journal of Sedimentary Research, 66, 100-106.

Garver, J. I., Scott, T. J. (1995). Trace elements in shale as indicators of crustal provenance and terrane accretion in the southern Canadian Cordillera. Geological Society of America Bulletin, 107(4), 440-453.

Gaugris, K. A., Grahn, Y. (2006). New chitinozoan species from the Devonian of the Paraná Basin, south Brazil, and their biostratigraphic significance. Ameghiniana, 43(2), 293-310.

Grahn, Y. (1992). Revision of Silurian and Devonian strata of Brazil. Palynology, 16, 35-61.
Grahn, Y., Bergamaschi, S., Pereira, E. (2002). Middle and Upper Devonian chitinozoan biostratigraphy of the Paraná Basin in Brazil and Paraguay. Palynology, 26, 135-165.

Grahn, Y., Mauller, P. M., Bergamaschi, S., Bosetti, E. P. (2013). Palynology and sequence stratigraphy of three Devonian rock units in the Apucarana Sub-basin (Paraná Basin, south Brazil): Additional data and correlation. Review of Palaeobotany and Palynology, 198, 27-44.

Grahn, Y., Mendlowicz Mauller, P., Pereira, E., Loboziak, S. (2010). Palynostratigraphy of the Chapada Group and its significance in the Devonian stratigraphy of the Paraná Basin, south Brazil. Journal of South American Earth Sciences, 29, 354-370.

Grahn, Y., Pereira, E., Bergamaschi, S. (2000). Silurian and Lower Devonian chitinozoan biostratigraphy of the Paraná Basin in Brazil and Paraguay. Palynology, 24, 143-172.

Gromet, L. P., Dymek, R. F., Haskin, L. A., Korotev, R. L. (1984). The "North American Shale Composite": its compilation, major and trace element characteristics. Geochimica et Cosmochimica Acta, 48, 2469-2482.

Hassan, S., Ishiga, H., Roser, B. P., Dozen, K., Naka, T. (1999). Geochemistry of Permian-Triassic shales in the Salt Range, Pakistan: implications for provenance and tectonism at the Gondwana margin. Chemical Geology, 158, 293-314.

Heinrich, E. W. (1972). Petrografía microscópica. 2. ed. Lisboa: Omega.

Herron, M. M. (1988). Geochemical classification of terrigenous sands and shales from core or log data. Journal of Sedimentary Petrology, 58, 820-829.

Horodyski, R. S., Holz, M., Grahn, Y., Bosetti, E. P. (2014). Remarks on sequence stratigraphy and taphonomy of the Malvinokaffric shelly fauna during the KAČÁK Event in the Apucarana Sub-basin (Paraná Basin), Brazil. International Journal of Earth Sciences, 103, 367-380.

Lacerda Filho, J. W., Silva, M. G., Jost, H. (2006). Geologia e Recursos Minerais do Estado de Mato Grosso do Sul (Programa Integração, Atualização e Difusão de Dados de Geologia do Brasil). Convênio CPRM/SICMEMS, MME.

Lange, F. W., Petri, S. (1967). The Devonian of the Paraná Basin. Boletim Paranaense de Geociências, 21(22), 5-55.

McCann, T. (1991) Petrological and geochemical determination of provenance in the southern Welsh Basin. Geological Society Special Publication, 57, 215-230.

McLennan, S. M., Hemming, S., McDaniel, D. K., Hanson, G. N. (1993). Geochemical approaches to sedimentation, provenance, and tectonics. Geological Society of America. Special Paper, 284. 
McLennan, S. M., Taylor, S. R. (1991). Sedimentary rocks and crustal evolution: tectonic setting and secular trends. The Journal of Geology, 99, 1-21.

Milani, E. J. (1997). Evolução tectono-estratigráfica da Bacia do Paraná e o seu relacionamento com a geodinâmica fanerozóica do Gondwana Sul-ocidental. Tese (Doutorado). Porto Alegre: Instituto de Geociências - UFRGS.

Milani, E. J., Melo, J. H. G., Souza, P. A., Fernandes, L. A., França, A. B. (2007). Bacia do Paraná. Boletim de Geociências da Petrobrás, 15(2), 265-287.

Mongelli, G. (1995). Trace elements distribution and mineralogical composition in the $<2$-Am size fraction of shales from the southern Apennines. Mineralogy and Petrology, 53, 103-114.

Mongelli, G., Cullers, R. L., Muelheisen, S. (1996). Geochemistry of Late Cretaceous-Oligocene shales from the Varicolori Formation, southern Apennines, Italy: implications for mineralogical, grain-size control and provenance. European Journal of Mineralogy, 8, 733-754.

Montibeller, C. C. (2015). Características químicomineralógicas e cerâmicas da matéria-prima utilizada pelo polo cerâmico de Rio Verde de Mato Grosso, MS. Dissertação (Mestrado). Rio Claro: Instituto de Geociências e Ciências Exatas - UNESP.

Montibeller, C. C., Zanardo, A. (2014a). Nível fosfático da Formação Ponta Grossa em Rio Verde de Mato Grosso, MS. $47^{\circ}$ Congresso Brasileiro de Geologia. Salvador: SBG.

Montibeller, C. C., Zanardo, A. (2014b). Petrografia de alguns níveis da Formação Ponta Grossa em Rio Verde de Mato Grosso, MS. $47^{\circ}$ Congresso Brasileiro de Geologia. Salvador: SBG.

Nesbitt, H. W., Young, G. M. (1982). Early Proterozoic climate sand plate motions inferred from major element chemistry of lutites. Nature, 299, 715-717.

Pearce, T. J., Bealy, B. M., Wray, D. S., Wright, D. K. (1999). Chemostratigraphy: a method to improve interwell correlation in barren sequences-case study using onshore Duckmantian/Stephanian sequences (West Midlands, UK). Sedimentary Geology, 124, 197-220.

Pereira, E., Carneiro, C. D. R., Bergamaschi, S., Almeida, F. F. M. (2012). Evolução das Sinéclises Paleozoicas: províncias Solimões, Amazonas, Parnaíba e Paraná. In: Y. Hasui, C. D. R. Carneiro, F. F. M. Almeida, A. Bartorelli (Orgs.), Geologia do Brasil, Cap. 5, 374-394. São Paulo: Beca.

Petrelli, M., Poli, G., Perugini, D., Peccerillo, A. (2005). Petrograph: a new software to visualize, model, and present geochemical data in igneous petrology. DOI 10.1029/2005GC000932.
Pettijohn, F. J. (1963). Data of Geochemistry: chemical composition of sandstones: excluding carbonate and volcanic sands (6a ed). Geological Survey. (Professional Paper, 440).

Raza, M., Ahmad, A. H. M., Khan, M. S., Khan, F. (2012). Geochemistry and detrital modes of Proterozoic sedimentary rocks, Bayana Basin, north Delhi fold belt: implications for provenance and source-area weathering. International Geology Review, 54(1), 111-129.

Rollinson, H. R. (1993). Using geochemical data: evaluation, presentation, interpretation. Harlow: Longman.

Roser, B. P., Korsch, R. J. (1986). Determination of tectonic setting of sandstone-mudstone suites using $\mathrm{SiO} 2$ content and K2O/Na2O ratio. The Journal of Geology, 94, 635-650.

Roser, B. P., Korsch, R. J. (1988). Provenance signatures of sandstone-mudstone suites determined using discriminant function analysis of major-element data. Chemical Geology, 67, 119-139.

Rudnick, R. L., Gao, S. (2003). Composition of the continental crust. In: H. Holland, K. Turekian (Eds.), Treatise on Geochemistry, 3, 1-70. Amsterdam: Elsevier.

Ryan, K. M., Williams, D. M. (2007). Testing the reliability of discrimination diagrams for determining the tectonic depositional environment of ancient sedimentary basins. Chemical Geology, 242, 103-125.

Selvaraj, K., Chen, C. T. A. (2006). Moderate chemical weathering of subtropical Taiwan: constraints from solidphase geochemistry of sediments and sedimentary rocks. The Journal of Geology, 114(1), 101-116.

Taylor, K. G., Macquaker, J. H. S. (2000). Spatial and temporal distribution of authigenic minerals in continental shelf sediments: implications for sequence stratigraphic analysis. Marine Authigenesis: From Global to Microbial, 66, 309-323.

Taylor, S. R., McLennan, S. M. (1981). The composition and evolution of the continental crust: rare earth element evidence from sedimentary rocks. Philosophical Transactions of the Royal Society A, 301, 381-399.

Velde, B. (2013). Green clay minerals. In: H. Holland, K. Turekian. Treatise on Geochemistry (2a ed.), 9, 351-364. Amsterdam: Elsevier.

Weaver, C. E. (1989). Clays, muds and shales. Developments in Sedimentology, 44, 819 p. Amsterdam: Elsevier.

Zabini, C., Holz, M., Bosetti, E. P., Matsumura, W. M. K., Horodyski, R. S. (2012). Sequence stratigraphy and taphonomic signatures of marine invertebrates: a Devonian (Pragian/ Eifelian) example of the Paraná Basin, Brazil. Journal of South American Earth Sciences, 33, 8-20. 